Florida International University FIU Digital Commons

6-24-2014

\title{
Canopy Gaps as Foci of Succession in a Florida Keys Tropical Hardwood Forest
}

Joshua M. Diamond

jdiam009@fiu.edu

DOI: $10.25148 /$ etd.FI14071143

Follow this and additional works at: https://digitalcommons.fiu.edu/etd

\section{Recommended Citation}

Diamond, Joshua M., "Canopy Gaps as Foci of Succession in a Florida Keys Tropical Hardwood Forest" (2014). FIU Electronic Theses and Dissertations. 1474.

https://digitalcommons.fiu.edu/etd/1474

This work is brought to you for free and open access by the University Graduate School at FIU Digital Commons. It has been accepted for inclusion in FIU Electronic Theses and Dissertations by an authorized administrator of FIU Digital Commons. For more information, please contact dcc@fiu.edu. 


\title{
FLORIDA INTERNATIONAL UNIVERSITY
}

\author{
Miami, Florida
}

\section{CANOPY GAPS AS FOCI OF SUCCESSION IN A FLORIDA KEYS TROPICAL HARDWOOD FOREST}

\author{
A thesis submitted in partial fulfillment of \\ the requirements for the degree of \\ MASTER OF SCIENCE \\ in \\ ENVIRONMENTAL STUDIES \\ by
}

Joshua M. Diamond 
To: Interim Dean Michael R. Heithaus

College of Arts and Sciences

This thesis, written by Joshua M. Diamond, and entitled Canopy Gaps as Foci of Succession in a Florida Keys Tropical Hardwood Forest, having been approved in respect to style and intellectual content, is referred to you for judgment.

We have read this thesis and recommend that it be approved.

$\begin{array}{r}\text { Keqi Zhang } \\ \hline \text { Jennifer Rehage } \\ \hline \text { Michael S. Ross, Major Professor }\end{array}$

Date of Defense: June 24, 2014

The thesis of Joshua M. Diamond is approved.

Interim Dean Michael R. Heithaus

College of Arts and Sciences

Dean Lakshmi N. Reddi

University Graduate School

Florida International University, 2014 


\title{
ABSTRACT OF THE THESIS \\ CANOPY GAPS AS FOCI OF SUCCESSION IN A FLORIDA KEYS TROPICAL HARDWOOD FOREST
}

by

\author{
Joshua M. Diamond
}

Florida International University, 2014

Miami, Florida

\section{Professor Michael S. Ross, Major Professor}

Canopy gaps in many forests are thought of as resetting the successional sequence due to increased light availability. In this study, canopy gaps were identified with a LiDAR digital canopy model in a Key Largo hardwood forest. Sapling structure and composition were recorded in the gaps. Weighted averaging calibration was applied to relative abundances of trees to determine the successional age optimum for each tree species, and weighted averaging regression was used to calculate inferred stand ages for each gap's saplings. The inferred stand ages were greater in young forest gaps than in surrounding, unimpacted forest, suggesting that succession was actually advanced. Canopy heights in Key Largo were shorter than many other tropical and temperate forests, canopy gaps were smaller and therefore light availability did not vary with gap area. This suggests that the largest gaps may not be big enough to produce the light conditions required to reestablish pioneer tree species. Soil and water conditions in young forest gaps may also favor mature rather than pioneer species. Resetting of the forest successional sequence may not occur without intense disturbances such as fires or major hurricanes that remove the entire canopy and consume or erode soils. 


\section{TABLE OF CONTENTS}

CHAPTER

PAGE

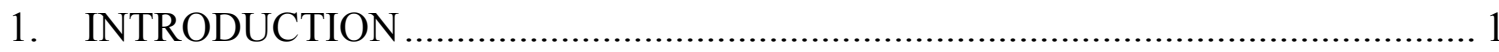

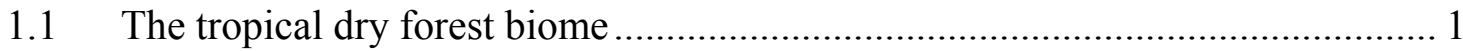

1.2 South Florida tropical hardwood hammocks …………………………………... 3

1.3 Change and succession in tropical hardwood hammocks ...................................... 6

1.4 Canopy gaps as foci of succession ..............................................................

1.5 Use of LiDAR to measure canopy gaps ......................................................... 10

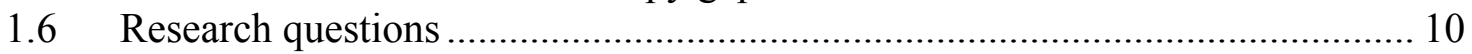

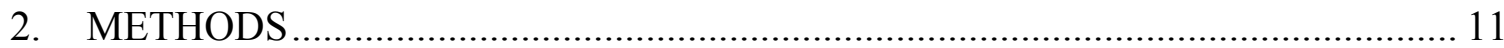

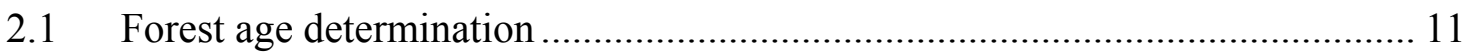

2.2 Creating digital elevation, digital surface, and digital canopy models .............. 12

2.3 Canopy height determination ..................................................................... 13

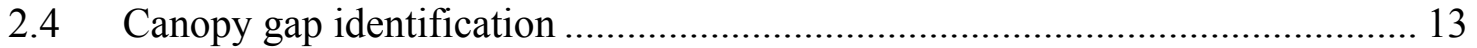

2.5 Study site selection .................................................................................. 14

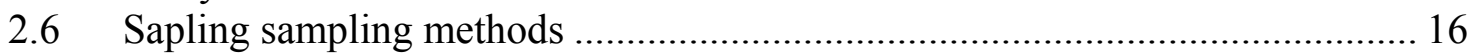

2.7 Collection and usage of existing transect data ................................................... 16

2.8 Determination of the cause of canopy gap formation ..................................... 17

2.9 Measurement of forest overstory density ………......................................... 19

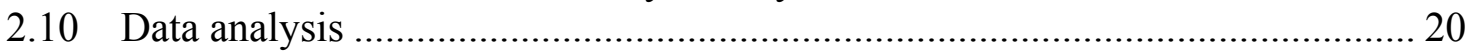

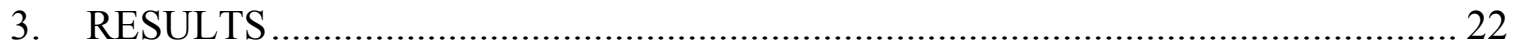

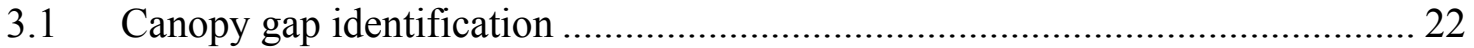

3.2 Gaps in existing forest composition transects .............................................. 22

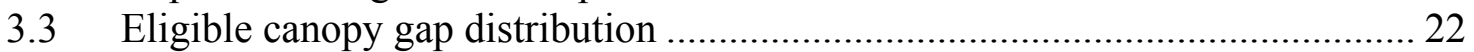

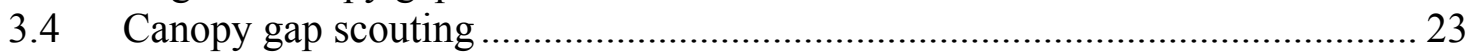

3.5 Geographic distribution of canopy gap formation ........................................... 23

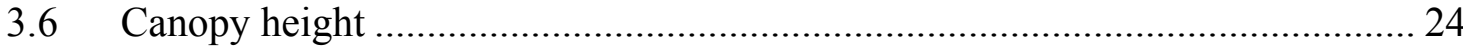

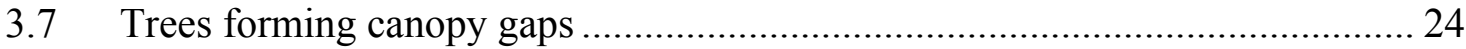

3.8 Sapling density across age and size classes ................................................... 25

3.9 Comparison of sapling densities between canopy gaps and intact forest

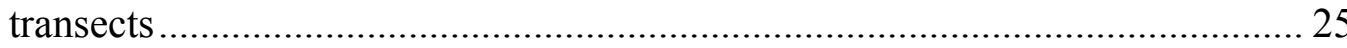

3.10 Relative successional status of gap understory saplings and overstory trees..... 26

3.11 Relative successional status of gap and transect saplings …………………...... 27

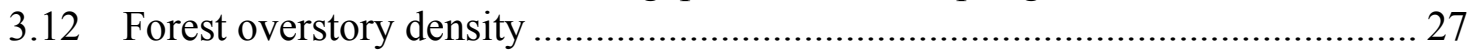

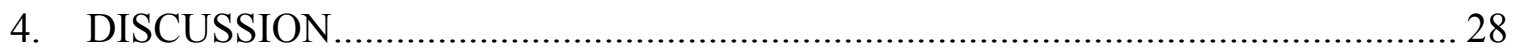

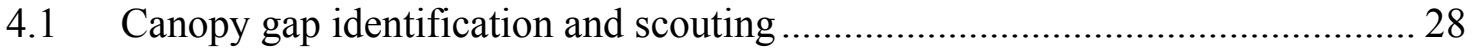

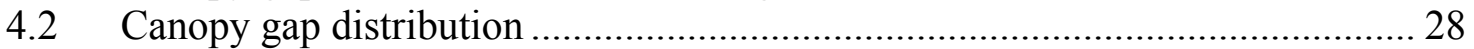

4.3 Sapling densities across age and size classes ..................................................... 29

4.4 Comparison of sapling densities between canopy gaps and intact forest transects ........................................................................................................ 30 
4.5 Relative successional status of gap understory saplings and overstory trees.... 30

4.6 Relative successional status of gap and transect saplings ............................... 32

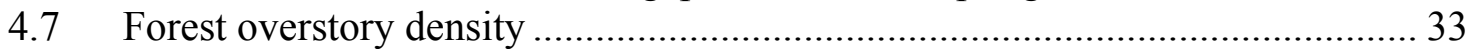

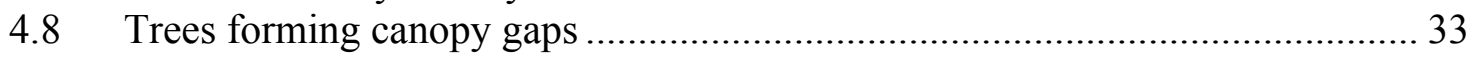

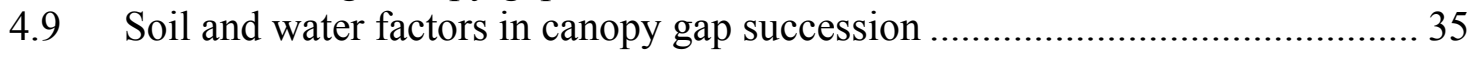

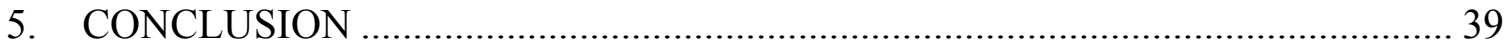

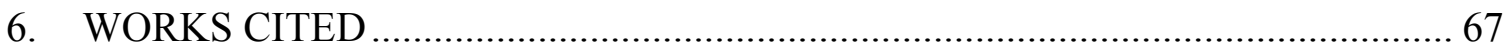




\section{LIST OF TABLES}

TABLE

PAGE

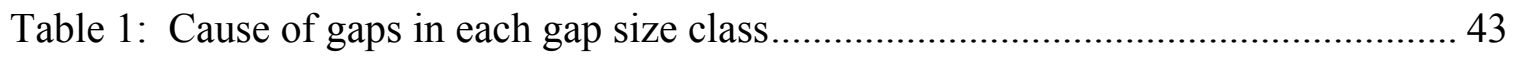

Table 2: Cause of canopy gaps in each forest age class .......................................... 43

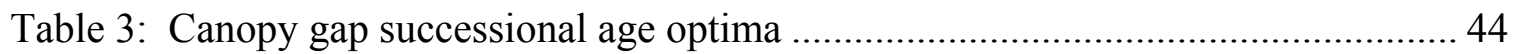

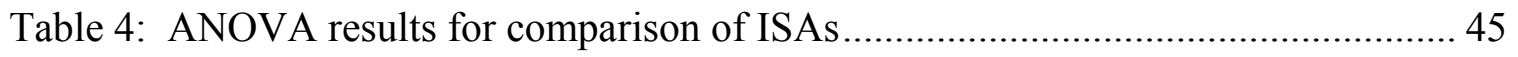

Table 5: Cause and geographic position of canopy gaps ........................................ 45 


\section{LIST OF FIGURES}

FIGURE

PAGE

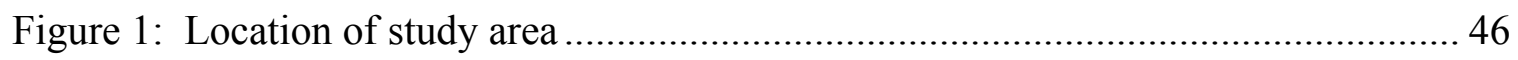

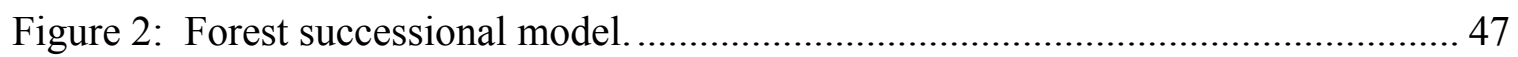

Figure 3: Early successional forest mortality model..................................................... 48

Figure 4: Canopy gap replacement model ................................................................ 48

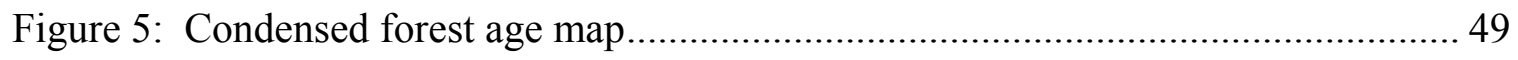

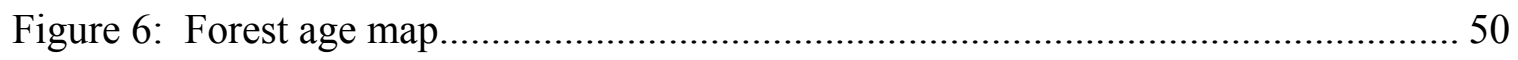

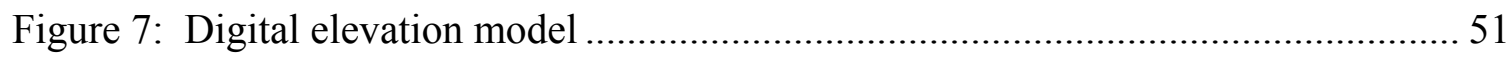

Figure 8: Digital surface model …………………….......................................... 52

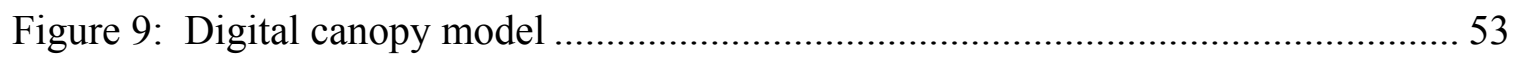

Figure 10: Neighborhood focal raster model ............................................................ 54

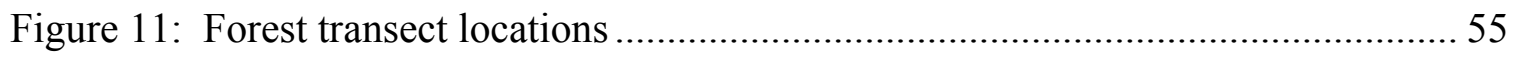

Figure 12: Distributions of age and size of forest canopy depression. ........................... 56

Figure 13: Gap scouting - cause of canopy gaps........................................................... 57

Figure 14: Canopy height histogram........................................................................ 58

Figure 15: Trees forming canopy gaps ................................................................... 59

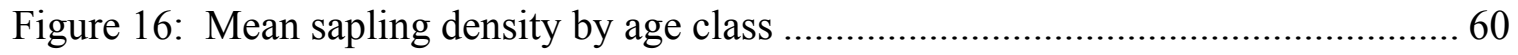

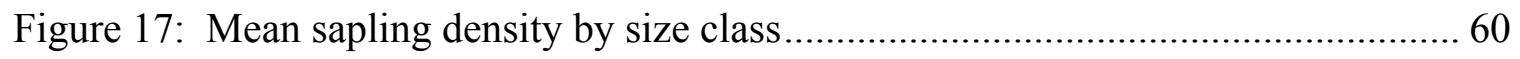

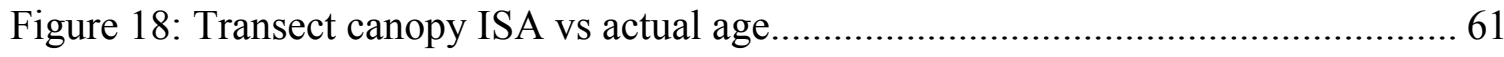

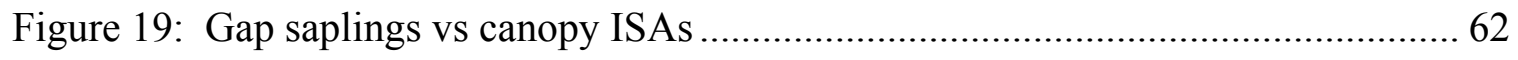

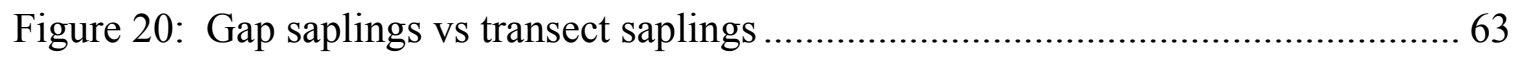

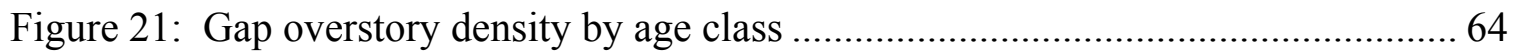




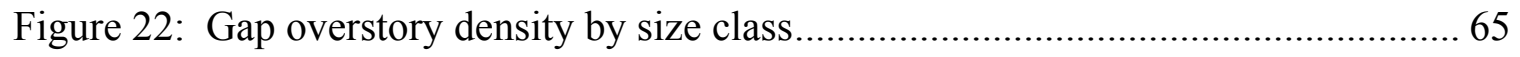

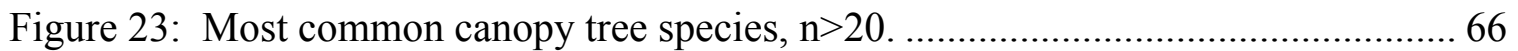




\section{INTRODUCTION}

\subsection{The tropical dry forest biome}

Seasonally dry forests have been the most degraded terrestrial tropical ecosystems. They have the longest history of human use in both the Old and New Worlds, and their current status reflects the heavy use of the past. Virtually no tropical dry forest remains unscathed by at least minor anthropogenic disturbance, and globally these forests are still the most at risk for conversion to agricultural fields, pastures, and in South Florida, urban development. Wet and dry tropical forests have a greater number of tree species than their temperate counterparts; a hectare of temperate forest may have 515 species, but a hectare of tropical forest could contain 50-100 species (Richards 1957 in Ricklefs 1977). Tropical dry forests are defined by the amount and seasonal distribution of rainfall, between 250 and $2000 \mathrm{~mm}$ annually (Murphy and Lugo 1986). Drawing boundaries between forest types based on rainfall is clearly difficult, to quote Ghazoul (2012), “...what is clear is that aseasonal tropical wet forests grade almost imperceptibly into seasonally dry evergreen forests, variably deciduous forest and, ultimately, xerophytic woodland at the other extreme." A key defining feature of the rainfall regime is the existence of a pronounced dry season, which is predictable and regular. In the Neotropics, the dry season usually lasts from 4-6 months, and in Asia from 2-6 months, however large variations based on local climatic conditions are recognized (Ghazoul 2012, Murphy and Lugo 1995, Murphy and Lugo 1986). The length of the dry season is 
also linked to distance to the equator, with dry seasons as short as several weeks in the equatorial summers (Murphy and Lugo 1986).

Logging has been a major factor in the loss of tropical dry forests, both historically and presently. The dry tropical forests have a lower canopy height and fewer strata of vegetation than moist and wet forests, making logging easier, and allowing easier access in the dry season (Murphy and Lugo 1986). Intensive logging in these forests is still continuing. For example, Mexico is experiencing deciduous tropical dry forest loss at an estimated rate of 1.4-2\% each year (Barreda-Bautista et al. 2011). By the year 2000, it was estimated that Mexico had seen 73\% of its tropical dry forest "altered, degraded, or converted mainly into agricultural or livestock grasslands" (Trejo and Dirzo 2000 in Barreda-Bautista et al. 2011).

Once trees have been removed, the soil and weather of the tropical dry forest may be very conducive to agriculture. These environments have supported the densest agricultural activity in the tropics and continue to do so today (Barreda-Bautista et al. 2011). Certain cereal crops may be drowned, stunted, or otherwise unable to grow in conditions of daily rain, heavy cloud cover, or other rainforest weather combinations. Soil conditions also favor agriculture in the dry tropics. "Dry forest soils are often more fertile, because less leaching occurs in the subhumid environment, and weeds and successional vegetation tend to be less aggressive...” (Murphy and Lugo 1986). Along with planting cropland, the dry tropical zones are the most utilized for grazing animals. Since the 1990s, the explosion in conversion to pasture land has been the largest driver of tropical dry forest loss (Maass 1995). 
In South Florida's tropical dry forests, the largest current threat is the spread of urban and suburban development. Unlike logging, crop production, or ranching, urban development in South Florida usually results in a permanent transformation of the landscape, to which tropical forests will not return. As South Florida's population continues to grow, the likelihood of urban areas being abandoned to forest succession decreases.

\subsection{South Florida tropical hardwood hammocks}

The Florida Keys are an archipelago extending about $350 \mathrm{~km}$ from southeastern Florida. This low lying island chain is home to a type of tropical dry forest known locally as tropical hardwood hammocks. The tropical hardwood hammock environment only exists in the United States in extreme southern Florida. These habitats form on higher and drier land than the surrounding freshwater marsh of the Everglades in peninsular Florida. As the highest elevation and least flood-prone habitats in south Florida, these were some of the first areas lost to agriculture and urban development, along with the Pinus elliottii densa dominated pine rockland habitats. The largest remaining stands of tropical hardwood hammocks are found in the upper Florida Keys, in

particular Key Largo (Figure 1). The hardwood hammocks are closed canopy forests with canopies dominated by a wide variety of evergreen and deciduous species, many of which produce fruits and mast of high importance to wildlife (Karim and Main 2009). Much of the vegetation is West Indian in origin, in contrast to the majority of vegetation of the east coast of the United States. Further north, temperate hardwood hammocks share some of the same Caribbean species, as well as a mixture of temperate trees like 
Quercus virginiana. Other sites in the West Indies have been documented to have a similar vegetation species composition to forests in the Florida Keys (Ross, O'Brien, and Flynn 1992). The tropical hardwood hammocks form over fairly thin, well-drained, organic soils (Ross, Coultas, and Hsieh 2003). The soils are created from litterfall and root senescence, followed by a process of rapid litter decomposition. Measured litter decomposition ranged from $18-52 \%$ within one year, $30-62 \%$ over two years (Ross, Coultas, and Hseih 2003). The hardwood hammock canopy is shorter than that of many other forests, and the influence of regular hurricanes may limit the overall height of trees in the region. Non-native species, such as the Category 1 invasive tree Australian Pine, grow much taller than native trees, but are more likely to die in storms (Duryea et al 1996).

A 2005 study by Thomas W. Gillespie examined the woody-plant species richness and densities in South Florida, exploring differences based on location and leaf phenology. The study indicated that woody-plant species richness was higher in the islands of the Florida Keys than in similar mainland sites (Gillespie 2005). The Upper Keys had the highest number of deciduous and evergreen species, and the highest density of deciduous species. The density of evergreen species was higher in the Lower Keys. More deciduous species were found in the Keys, compared to the mainland (Gillespie 2005). 164 different woody plant species have been documented in the Florida Keys, however not all of these are represented in the hardwood hammock environment (Armentano et al. 2002).

The largest areas of hammocks occur in North Key Largo. Key Largo contains not only the largest extent of hardwood hammock habitat (1,834 ha) but also the largest 
amount of hardwood hammock under protection for conservation purposes $(1,024 \mathrm{ha})$ (Karim and Main 2009). North Key Largo has two main conservation areas, bisected by County Road 905. On the Northwest side of the road, the hammock is protected by the Crocodile Lake National Wildlife Refuge. The Southeast side of the road is managed by the Dagny Johnson Key Largo Hammock Botanical State Park.

A study by Ross et al (1992) divided the Florida Keys into 13 Ecological Site Units based on vegetation and ecosystem characteristics. Two major environmental gradients determined the arrangement of these units: an elevation gradient on each island, as well as a geographic gradient based on the island's position in the archipelago (Ross, O'Brien, and Flynn 1992). According to this classification, the hardwood hammocks of North Key Largo are categorized in two groups: Medium and High Productivity Rockland Hammocks.

As many of the tropical hardwood hammocks in peninsular Florida have been lost to development, the hammocks of Key Largo and other Florida Keys can prove useful to research and restoration of hammocks of mainland sites. Since many of the Keys were not subject to as much human disturbance as the South Florida mainland since the 1930s, and the forests were not used as intensively by Native Americans as were the hardwood hammock tree islands in the Everglades, they may serve as reference sites for directing proper restoration on the mainland. Some of these hammocks have been undisturbed for long enough to qualify as old-growth (Ross et al. 2010). 


\subsection{Change and succession in tropical hardwood hammocks}

Succession is a process of community development that is reasonably predictable, and results from physical modification of the environment by the community (Odum 1969). It can be observed through the change over time of species composition and community structure in a defined area (Pickett 1979). These successional changes create gradients of physical and biotic environments, which species can adapt to on an evolutionary timescale, just as they would evolve to particular climatic or elevation gradients (Pickett 1979). This allows for the sorting of species into different successional positions, in conjunction with the disturbance regime. Pioneer species should proliferate in a high disturbance and low stress environment where competition for resources is minimal, while mature forest species should tolerate stress in the absence of major disturbance, and successfully compete against the pioneers (Grime 1977). The seedlings of climax species should be able to survive in shade for multiple years (Whitmore 1989). In this way, successional forces shape the diversity of the forest ecosystem. For instance, in abandoned agricultural land succession in Illinois, plant species diversity was shown to increase with succession, reaching a maximum when structural diversity was highest, allowing for temporary coexistence of shade-tolerant and shade-intolerant species (Bazzaz 1975).

Woody plant succession has been observed in the tropical hardwood hammocks of Key Largo (Figure 2). Ross et al. (2001) described a species compositional sequence for this forest. Most of the pioneer species, such as Lysiloma bahamensis, have droughtdeciduous leaf phenology, while all of the mature forest species, like Drypetes 
diversifolia, have an evergreen leaf phenology (Ross et al. 2001). In forests sampled immediately after Hurricane Andrew in 1992 pioneer species incurred higher mortality rates than mature forest species (Figure 3), indicating the disturbance effect of a hurricane advanced the overall successional pattern of the forest, rather than inhibiting succession (Ross et al. 2001). In a subsequent paper, Carrington et al. (unpublished manuscript) showed that understory seedlings and saplings several years after the hurricane were primarily late-successional further indicating that hurricanes accelerate the successional process in tropical hardwood hammocks.

\subsection{Canopy gaps as foci of succession}

Although community change has been recognized in Key Largo forests, the mechanisms driving this change remain poorly understood. Many factors are recognized to shape the forests currently visible today. Hurricanes can dramatically alter forest composition and structure, breaking branches and killing trees. In the seasonally dry tropical forests of the Caribbean, hurricanes have been shown to cause higher mortality among deciduous tree species than their evergreen counterparts (Ross et al. 2001, Brokaw and Grear 1991). The colonization of gaps following a disturbance can also create a pathway for change between vegetation communities (Figure 4).

Canopy gaps have been studied as the basic unit of turnover in forested communities, providing a temporary spatial heterogeneity. A gap is defined as a hole in the forest extending from the canopy down to a mean height of at least two meters above the ground surface (Brokaw 1982). Gaps can form irregular shapes, with the classic gap shape being described as "chablis," a dumbbell-like shape formed as the tree crown 
brings other branches down with it, but with the trunk bringing down less vegetation (Brokaw 1985). The gaps are most often associated with falling trees, but gaps can also be created by falling limbs, as well as fires sparked by lightning strikes. 20 meters squared is the minimum gap size usually recognized for study (Brokaw 1982). Most of these gaps are small, but a disproportionate amount of the overall gap-area can be attributed to the largest of the canopy gaps (Brokaw 1982 in Brokaw 1985).

Ricklefs (1977) argues that canopy gaps in tropical forests introduce larger temporary environmental gradients than in temperate forests. He cites the concentration of nutrients in aboveground vegetation, high sun angle, and the rapid rate of leaf litter decomposition and mineral leaching as factors that cause canopy gaps to have a more profound effect on the future diversity of the microsite in the tropics (Ricklefs 1977). These effects may be even greater in the largest gap sizes, creating such large gradients in sunlight and moisture that only pioneer species may colonize the site. Whitmore (1989) expands on the differences in large and small canopy gaps, dividing all trees into climax species that germinate under the closed canopy, and are released from suppression by a small canopy gap, and pioneer species that germinate only in the full sunlight of a large gap. Denslow (1980a) agrees that the size of gap opening should affect the microclimate of the gap and thus the type of species that should be able to be established. Due to canopy gaps, we may not be able to consider the true age of the forest the time since oldfield succession began, but the time since a canopy gap has formed (Ricklefs 1977).

Gap turnover and succession has been particularly well studied in tropical rainforests, where data suggest that the canopy gap acts as a temporary reset of the successional sequence, allowing pioneer species to infiltrate the forest, contributing to the 
high tree species diversity across the biome (Ricklefs 1977, Denslow 1980b, Denslow 1987, Vandermeer et al. 2000, Schnitzer, Mascaro, and Carson 2008). There appears to be a consensus about the role of gaps in this environment, but across the environmental gradient of rainfall and seasonality, there is less agreement about the role that gaps may have.

Canopy gaps may play a different role in seasonally dry tropical forests than in their rainforest counterparts. Several factors suggest that canopy gaps in the dry tropics should be smaller and occur less frequently than in rainforests. Dickinson, Hermann, and Whigham (2001) suggest numerous factors that could explain lower rates of background disturbance in the dry tropics. Lower annual rainfall and seasonal drought should select for trees with large diameter to height ratios and smaller crowns, thus the gaps created should be smaller. Greater tree stability in dry tropical forests leads to less mortality and fewer gaps, while the stability also results in more standing deaths and smaller gaps (Dickinson, Hermann, and Whigham 2001). Among the driest tropical forests, gap phase dynamics do not appear to exist (Swaine, Lieberman, and Hall 1990 in Dickinson, Hermann, and Whigham 2001). If the dynamics of canopy gap species replacement in South Florida are more similar to a dry tropical model, the forest may have few gaps that are small and are repopulated by late successional species, instead of resetting the seral sequence.

The sapling species growing in a gap provides an indication of the successional sequence. If a gap in a young forest is dominated by late successional saplings, the gap is advancing the successional stage of the forest. Alternatively, the gap could be allowing pioneer species to regenerate, therefore temporarily reversing the direction of 
successional change, or recruiting saplings exclusively from the same species present around the gap edge with little effect on the successional process. In Key Largo, we can find gaps that were present in 2008 using light detection and ranging (LiDAR) canopy models, and determine the successional status of saplings currently growing in these locations and the surrounding forests.

\subsection{Use of LiDAR to measure canopy gaps}

LiDAR can be a powerful tool for studying forest structure and canopy gaps. The airborne LiDAR data produces a cloud of georeferenced points. From these points, rasters can be interpolated to create a digital surface model (DSM) of the upper canopy, and a digital elevation model (DEM) of the forest floor. By subtracting DEM from DSM, a digital canopy model (DCM) emerges, showing the outer shape of the forest (Zhang 2008, Asner et al. 2013). From the DCM, canopy gaps extending down to at least 2 meters above the ground and with an area of at least $20 \mathrm{~m}^{2}$ can be identified remotely (Asner et al. 2013).

\subsection{Research questions}

The topics addressed by this project revolve around the role of canopy gaps in the succession of tropical hardwood hammock forests. In order to better understand the function of canopy gaps, this study aimed to answer several questions: 1. How are canopy gaps distributed in this forest? Are gaps distributed evenly among age classes of the forest, or does the percent of forest in gap phase change with the stand age? 2. How does the overall height of the canopy relate to the age of the forest, and how will the 
forest height relate to sizes and distribution of canopy gaps? 3. How do gaps in the forest relate to tree sapling density? Do gaps have higher densities of saplings than the surrounding hardwood hammock? 4. How do gaps alter the successional status of the forest? Do saplings growing in the gaps represent later successional stages than the forest canopy, or understory outside the gap? 5. How does forest overstory density change across gap features? Is overstory density related to gap size, forest age, gap sapling species composition, or canopy species composition? 6. How do gaps in Key Largo compare to gaps in other forests in the seasonally dry tropical forest biome? How do these gaps compare to gaps occurring in other biomes, such as the tropical rainforest?

\section{METHODS}

\subsection{Forest age determination}

Ages of forest areas were determined by analyzing a time series of aerial photographs. Low resolution images were available for North Key Largo from as early as 1928. Subsequent higher resolution photos were available in 1940, 1959, 1971, 1985, and 1992. The 1928 photographs do not cover the entire study area, so assignment to the oldest forest class was interpreted by comparing aerial forest appearance in 1940 to plots known to be forested in 1928. To compare forest changes over the time sequence, forests under 43 years of age were categorized as "young." Forests between 44 and 74 years of age were categorized as "middle aged." Forests over 75 years old were categorized as "mature" (Figure 5). More precise forest ages were used to assess species assemblage 
positions along the successional gradient, assuming forest age to be at a midpoint between each set of observations (Figure 6).

\subsection{Creating digital elevation, digital surface, and digital canopy models}

LiDAR data collected by the Florida Division of Emergency Management was used to create a digital canopy model (DCM) of the height of the forest. The data (publicly available through Florida International University at www.digir.fiu.edu/lidar) was collected between January and February 2008. The LiDAR point cloud was flown at a density sufficient to support a four $\mathrm{ft}$ maximum resolution. This data was divided into $5000 \mathrm{ft}$ by $5000 \mathrm{ft}$ tiles. 20 LiDAR tiles were needed to cover the entire study area. In ArcMap, an LAS dataset was created from each individual tile, before being merged into a single dataset.

To create the DEM, a ground filter was applied to the LAS dataset, picking out the lowest elevation returns from each point cloud (Figure 7). The LAS Dataset to Raster tool was used to convert the LAS file to a raster graphic. Binning cell assignment type was set to average. Natural neighbor triangulation was used as the void filling method. 1.5 meter cells were used to avoid lost information. To create the DSM, a similar procedure was applied; but a filter on the LAS dataset was set to non-ground, and binning cell assignment type was set to maximum (Figure 8). A DCM containing canopy heights of the forest was created by subtracting the values of the DEM raster from the DSM raster, using the minus tool (Figure 9). Finally, the area of interest within the raster was extracted with the clip tool, using a forest boundary polygon drawn from aerial photographs as the extent. 


\subsection{Canopy height determination}

Canopy heights were determined using a separate DCM. The DCM used to locate canopy gaps was too fine in resolution for studying canopy height. At a fine scale, too many upper pixels identified vegetation lower than the canopy layer. This resulted in a

mean canopy height of approximately one half of the actual canopy height. Using a 10 meter cell size, the DCM successfully identified the upper surface and height of canopy trees. The 10 meter cell DCM produced over 87,000 pixels. Pixels were sorted according to canopy height, and alternate pixels were selected to produce a representative dataset for analysis.

\subsection{Canopy gap identification}

Focal statistics were applied to the DCM. The focal statistics performed a neighborhood operation that computed an output raster where the value for each output cell is a function of the values of all input cells within a specified area (ESRI 2014). An area of $13 \times 131.5$ meter pixels is used, producing an area of $19.5 \times 19.5$ meters, 380.25 $\mathrm{m}^{2}$ (Figure 10). The neighborhood focal mean was used to produce an average canopy height within this area. The map algebra raster calculator was used to compare the neighborhood focal mean to the DCM. DCM pixels less than $1 / 2$ of the neighborhood focal mean were classified as canopy gap pixels. The output of this operation was a Boolean raster consisting of forest pixels and canopy gap pixels. Finally, the raster to 
polygon tool was used to convert the canopy gap model from contiguous groups of raster graphic pixels into individually selectable shapefiles. Canopy gap pixels were not necessarily treefall canopy gaps; further error-checking procedures (below, section 2.4) were used to improve the accuracy of the model.

\subsection{Study site selection}

45 gaps were randomly selected from the LiDAR canopy gap model, across two rounds of canopy gap sampling. In the initial round of sampling, five canopy gaps each were selected in all 9 combinations of gap size (small, medium, large) and forest age classes (young, middle aged, mature). The smallest gaps had a minimum area equivalent to a circle with a radius of 2.5 meters, with a maximum size of 3 meter radius. This produced a minimum area of $19.23 \mathrm{~m}^{2}$, in accordance with the Brokaw (1982) definition of a canopy gap. Medium sized gaps had an area equivalent to a circle with a radius of between 3 and 4 meters. Large gaps had an area equivalent to a circle with a minimum radius of 4 meters. The largest gap identified by the model had an area equivalent to a radius of approximately 6.5 meters. The objective of the initial round of canopy gap scouting was to determine the rate of success in gap identification and to refine the method for selecting naturally formed canopy gaps. In each canopy gap, lists of understory species (1-5 meters height) and canopy species (greater than 5 meters height) were compiled. The suspected cause of each canopy gap was recorded, including natural treefall gaps, areas of low canopy in a state of recovery from past fires, and canopy gaps associated with man-made features like stone piles, abandoned roads, concrete foundations, and artificial nests built for endangered Key Largo Woodrats (Table 1, Table 
2). Following the first round of canopy gap scouting, new parameters were imposed intending to narrow the selection of canopy gaps to naturally formed treefall gaps. The layer of canopy gaps identified by LiDAR was compared against the DEM, with a lower limit threshold set at 2 feet above sea level, in order to excluded coastal woodlands located at the shoreward edge of the hardwood hammock, dominated by shrubs, and small trees, particularly buttonwood (Conocarpus erectus). The shorter stature of this ecotone, nestled between taller hardwood hammock and fringing mangrove ecosystems, causes the appearance on the canopy model of long, thin strands of canopy gaps at the edge of the forest, parallel to the coastline. Buttonwood ecotone fragments were clipped from the canopy gap model. In addition, the 2 foot elevation threshold prevented the inclusion of solution holes, some dominated by short-stature emergent aquatic vegetation or terrestrial ferns like Nephrolepis exaltata. Two additional areas were excluded at the far north and far south of the island. An exclusion zone in the far north avoids hammocks recovering from fire; the regenerating forest has the appearance of numerous gaps on the canopy gap model. An exclusion zone in the far south avoids major anthropogenic disturbances, where large piles of limestone bedrock were created in a development project abandoned in the 1980s. Finally, before each new canopy gap was sampled, aerial imagery from Google Earth was inspected at each location to exclude gaps with anthropogenic origins such as abandoned roads. 23 natural treefall gaps found during the initial round of canopy gap scouting were sampled and included in the survey. An additional 22 canopy gaps were randomly selected from the same model to produce five natural canopy gaps each in all 9 combinations of gap size and forest age classes. 


\subsection{Sapling sampling methods}

Tree saplings were defined as all woody tree species, excluding vines, between 1 and 5 meters height. Saplings were classified into two height intervals, between 1-3 meters height, and 3-5 meters height. Saplings and seedlings less than 1 meter tall were not recorded. Species identification and height class were recorded for each individual sapling in circles of 2 meter radius. The number of circular sampling areas was scaled up by gap size: small gaps had one; medium, two; and large, three sample plots. This created a sampling area of $12.57,25.13$, and $37.70 \mathrm{~m}^{2}$ for small, medium, and large gaps, respectively. Small gaps were sampled in the gap center; larger gaps were sampled near the center.

\subsection{Collection and usage of existing transect data}

Forest species composition transects were established in North Key Largo by the South Florida Terrestrial Ecosystems Lab in 1993-1995, and were resampled in 20132014 (Figure 11). These transects were located mostly within 200 meters of County Road 905, which bisects the island. Belt transects 60-100 meters in length were established. Species and diameter at breast height (DBH) were recorded for trees rooted within 1 meter (stems $1.0-9.9 \mathrm{~cm} \mathrm{DBH}$ ) or 2 meters (stems $>10.0 \mathrm{~cm} \mathrm{DBH)} \mathrm{of} \mathrm{the} \mathrm{transect}$ center line. Trees with stems $\geq 25 \mathrm{~cm}$ DBH within 5 meters of the center line were also recorded (Ross et al 2001). Seedlings were recorded within 0.5 meters of the center line. Seedlings were classified as small $(<10 \mathrm{~cm}$ height), medium ( $10 \mathrm{~cm}-1 \mathrm{~m}$ height $)$, or large ( $>1$ meter height, $<1 \mathrm{~cm} \mathrm{DBH).} \mathrm{The} \mathrm{large} \mathrm{seedling} \mathrm{category} \mathrm{corresponded} \mathrm{to}$ 
measurements for small saplings in canopy gaps. The smallest category of trees, with stems between 1.0 and $4.9 \mathrm{~cm} \mathrm{DBH}$ were typically under 5 meters height, roughly equivalent to the large sapling category recorded in the canopy gaps. Larger trees were usually greater than 5 meters height; all other trees recorded were used as the canopy tree layer.

The LiDAR DCM identified several gaps in or within 5 meters of the existing forest transects. Using the measuring tool in ArcMap, locations where gaps intercepted the transects were identified. For analytical purposes, a total of 35 meters of these potential gap environments were removed from four separate transects.

\subsection{Determination of the cause of canopy gap formation}

In each canopy gap in the scouting and sampling phase, the primary cause of canopy gap creation was determined. The primary round of scouting was to determine which canopy gaps were naturally created treefall canopy gaps, and if so, what species were responsible for the formation of the gap. The LiDAR data was collected 6 years prior to in situ data, meaning that some of the gap-forming trees were in a state of decomposition. However, some were still alive years later, and while mostly uprooted, had new growths emerging from trunks or other stems that made them identifiable. Other gaps were formed by large stems breaking from living trees. When the stem matched scars on a neighboring tree, identification was possible. Even if dead, some species had characteristic shapes or remnant bark that allowed for identification years after death. When a gap-forming tree could not be identified, it was recorded as an unidentified tree. 
In each gap, the number of gap-forming trees and their species identities, when possible, were recorded.

If the gap was not created by a natural treefall, the cause of the gap was determined. In many cases, canopy gaps were created by a variety of anthropogenic actions. The majority of anthropogenic canopy gaps were caused by abandoned roads. Most paved roads were easily excludable from aerial photographs, but many gravel and dirt roads have persisted and were not easily identifiable. In many cases, this was complicated as trees had regrown on some sections of abandoned roads, while other patches remained only sparsely vegetated or completely barren. Creation of forest roads can result in soil compaction and reduced productivity via reduced porosity and water infiltration (Elseroad, Fulé, and Covington 2003). Although these abandoned roads do constitute a spatial heterogeneity in the forest, soil factors make them unsuitable for study alongside naturally formed treefall canopy gaps. When this cause could not be determined from aerial photographs, the substrate was inspected in situ to rule out some sites as anthropogenic in origin. Other anthropogenic canopy gaps have been created within the last few decades. In the southern portion of the study area, large hills of crushed limestone, approximately 10 meters high, remained in the wake of abandoned residential development which included a large saltwater canal connected to a lake. While they appear to have a low canopy on the DCM, the DEM reveals these features as unsuitable. Key Largo, like most of South Florida, is very flat, so these sites were excluded due to unusual topographic heterogeneity. In this area, there are also remnant concrete foundations from abandoned development. Scattered throughout the island are manmade nesting structures for the Key Largo Woodrat. These were built to provide 
supplemental reproductive shelter and increase the population of this endangered, endemic species, and some are large enough to appear as canopy gaps on the DCM.

Forest fires have made a considerable impact on forest structure, particularly in the northern section of the study area. The results of these fires are visible on aerial photographs. In mainland South Florida, the primary stage of forest succession following a fire in a tropical hardwood hammock forest is sometimes a Pine Rockland forest, with an open canopy dominated by Pinus elliottii densa. This forest also grows in the Lower Florida Keys, especially Big Pine Key. In the Upper Florida Keys, this species does not grow due to insufficiency in freshwater availability (Alexander 1974). In the absence of Pinus elliottii densa forest, tropical hardwood hammock begins to form in the burned areas. Growth and colonization is uneven, possibly reflecting the depletion of an already thin organic soil layer due to fire. The uneven growth appears in the DCM as numerous adjacent canopy gaps, which do not reflect the same origins being studied in natural treefall gap dynamics. Although the fire ecology of the Upper Florida Keys is worthy of study on its own, larger burned areas were excluded from the study area by examining aerial photographs. However, smaller burned areas, most likely from lightning strikes, were found in initial scouting, and were identified in situ from charred tree trunks, charred leaf litter, and the presence of a thin, visible charcoal layer in the soil.

\subsection{Measurement of forest overstory density}

Forest overstory density was measured with a spherical densiometer, following the methods established by Lemmon (1956). The densiometer was held 12" - 18" in front of the body at elbow height, with the user's head is just outside of the grid area. In 
the gridded sphere, the user assumes four equally spaced dots equivalent to quartersquare canopy openings. The total count is then multiplied by 1.04 to obtain percent of overhead area not occupied by the canopy. The difference between this count and 100 is the measurement of overstory density. Four readings are taken, in each of the cardinal directions. The four readings are averaged together. In each canopy gap, a set of four measurements is taken in each 2 meter radius plot. Where more than one plot was sampled, (for the medium and large gaps,) measurements of percent of overstory density were averaged together. Two-factor ANOVA with replication was used to compare forest story density across size classes of gaps and forest ages.

\subsection{Data analysis}

In order to determine the successional positions of different gap sapling cohorts, and gap, understory, and canopy tree assemblages, weighted averaging (WA) regression and calibration was performed with C2 version 1.4.2 (Juggins 2007). WA regression was performed on canopy tree relative abundances calibrated by successional age, creating a species-successional relationship. Each species successional age optimum was determined by abundance-weighted averaging in a calibration data set, where the environmental variable of stand age is known (Ross et al. 2001; Carrington et al., unpublished manuscript)

As in Ross et al. (2001) and Carrington et al. (unpublished manuscript), each species' successional age optimum $\widehat{S A O}_{k}$ was calculated as 


$$
\widehat{S A O}_{k}=\sum_{i=1}^{n} y_{i k} x_{i} / \sum_{i=1}^{n} y_{i k}
$$

and its tolerance (weighted standard deviation, $\hat{t}_{k}$ ) as

$$
\hat{t}_{k}=\left[\sum_{i=1}^{n} y_{i k} \frac{\left(x_{i}-\widehat{S A O}_{k}\right)^{2}}{\sum_{i=1}^{n} y_{i k}}\right]^{\frac{1}{2}}
$$

where $x_{i}$ is time since last land clearing in stand $i$ and $y_{i k}$ is relative abundance of species $k$ in stand $i(i=1, \ldots n$ stands and $k=1, \ldots m$ species $)$.

Classical deshrinking was used in WA regression to correct for a contraction in the range of estimated values (overestimates at the low end and underestimates at high values of the environmental variable) which comes from the double averaging during WA regression and calibration (ter Braak and van Damm 1989, in Ross et al. 2001).

To compare the successional stage of canopy gap saplings versus transect canopy trees, a WA model without downweighting by species tolerances was used to infer successional ages. An inferred stand age (ISA) was calculated for each site as

$$
I S A_{i}=\frac{\frac{\sum_{i=1}^{m} y_{i k} \widehat{S A O}_{k}}{\hat{t}_{k}^{2}}}{\sum_{i=1}^{m} y_{i k}}
$$

where $y_{i k}$ is the relative abundance of canopy tree species $i$, small saplings species $i$, or large sapling species $i$, in stand $k$. In order to test the effects of sapling cohort and stand age on successional position, two-way ANOVA was applied to small and large sapling ISAs in canopy gaps and transects in young, middle aged, and mature stands.

Canopy gap sapling densities were derived by dividing numbers of saplings by the area sampled. This procedure was repeated for small saplings, large saplings, and all 
saplings together in gaps as well as along intact forest transects. Saplings in the canopy gaps were compared by groups of age and size classes using two-factor ANOVA.

Saplings in transects were compared to saplings in gaps with paired t-tests to determine if the mean differences were $>0$.

\section{RESULTS}

\subsection{Canopy gap identification}

The LiDAR DCM included 3,121,531 pixels of eligible forest canopy. Of these, 68,244 pixels were classified as canopy gap pixels, representing $2.19 \%$ of the total forest. Most of these pixels, when grouped into continuous polygons, were smaller than $20 \mathrm{~m}^{2}$ in area and were excluded. 648 canopy gaps of requisite size were identified, and the area of these gaps represents $0.39 \%$ of total eligible forest area.

\subsection{Gaps in existing forest composition transects}

The LiDAR canopy gap model shows $1.22 \%$ of the total transect length to include canopy gaps, compared to $0.39 \%$ of the total eligible forest area.

\subsection{Eligible canopy gap distribution}

In North Key Largo, $18.9 \%$ of the forest is young, $42.4 \%$ is middle age, and $38.7 \%$ is mature. The young forests contained almost as many eligible canopy gaps as middle aged and mature forests combined (Figure 12). Young forests contained 278 
canopy gaps, middle age contained 143 canopy gaps, and mature contained 144 canopy gaps. Gaps comprised $1.05 \%$ of young forest area, $0.17 \%$ of middle age forest, and $0.18 \%$ of mature forest area. Across the entire forest, $0.34 \%$ of the forest was recorded as gap phase. In the young forest, 110 gaps were small, 124 were medium, and 44 were large. Middle age forests contained 70 small gaps, 58 medium gaps, and 6 large gaps. Mature forests contained 88 small gaps, 49 medium gaps, and 7 large gaps.

\subsection{Canopy gap scouting}

All 45 canopy gaps randomly selected in the initial scouting phase were found in the hardwood hammocks. Although all canopy gaps were located and confirmed, the gaps resulted from multiple sources (Figure 13). 25 of 45 canopy gaps were naturally

formed treefall gaps. 11 canopy gaps were determined to be of anthropogenic origin. Four canopy gaps each were determined to be solution holes, or forest patches in recovery from fires. One canopy gap was of indeterminate origin, with no direct evidence of a treefall, anthropogenic cause, fire, or unique geological situation.

\subsection{Geographic distribution of canopy gap formation}

Following the initial period of gap scouting, North Key Largo was divided into three regions, and gaps were sorted by what caused the gap to appear on the LiDAR model (Table 5). The northern portion of the island included small forest patches north of UTM 571231 E, $2706853 \mathrm{~N}$. The southern portion of the island included small forest areas south of UTM $564345 \mathrm{E}, 2785631 \mathrm{~N}$. The majority of the forest was categorized as the central forest, in between these two coordinates. The northern forest included large 
pockets of low elevation and solution holes. Many of these solution holes were filled with water and emergent hydrophilic vegetation, giving the solution hole the appearance of a canopy gap on the LiDAR model. In addition, the northern forest contained a large area that is recovering from a mid-1970s forest fire, and the uneven recovery of vegetation gives a contour pattern that resembles many canopy gaps close together. Half of the gaps in the northern forest were attributed to fire or solution holes (Table 5). The southern forest has a high density of relatively recent anthropogenic disturbances, which give the appearance of many canopy gaps on the LiDAR model. Over half of the gaps in the southern forest were anthropogenic in origin (Table 5). For these reasons, the northern and southern forest segments were excluded from further study, so that a higher proportion of natural treefall gaps would be selected.

\subsection{Canopy height}

Using the 10 meter cell size, the LiDAR DCM calculated a mean canopy height of 11.71 meters, with a standard deviation of 2.19 meters. The median height of the forest is 12.70 meters (Figure 14).

\subsection{Trees forming canopy gaps}

13 tree species in Key Largo were involved in the formation of canopy gaps. The greatest numbers of gap forming trees were unidentified, usually due to the state of decomposition (Figure 15). 130 gap-forming trees were observed across the 45 treefall gaps, a mean of 2.89 trees per gap. The three most common tree species identified in gap 
formation, L. bahamensis, C. diversifolia, and B. simaruba, were observed surviving after a treefall, growing new stems from the main fallen stem.

\subsection{Sapling density across age and size classes}

Mean sapling density per square meter increased with increasing stand age (mature: 1.14, middle aged: 1.00, young: 0.75) (Figure 16). Two-way ANOVA indicated sapling density varied significantly across forest age classes $(\mathrm{P}<0.01)$. Sapling density decreased with increasing canopy gap size, (small: 1.00, medium: 0.98, large: 0.92 ) but this difference was not significant ( $\mathrm{P}=0.7762$ ) (Figure 17). The forest age-by-gap size interaction was not significant $(\mathrm{P}=0.7099)$. In canopy gaps, the mean density of saplings per square meter was higher for small saplings than large saplings (mean density $\pm 95 \% \mathrm{CI}=$ small saplings: $0.55 \pm 0.09$, large saplings: $0.42 \pm 0.06, \mathrm{P}<0.01)$.

\subsection{Comparison of sapling densities between canopy gaps and intact forest transects}

Mean sapling densities did not vary significantly between canopy gaps and intact forest transects (mean sapling density $\pm 95 \% \mathrm{CI}=$ gap density: $0.97 \pm 0.10$, transect density: $0.92 \pm 0.15, P=0.3009$ ). The mean density of small saplings did not vary significantly between canopy gaps and intact forest transects (mean small sapling density $\pm 95 \% \mathrm{CI}=$ gap density: $0.55 \pm 0.08$, transect density: $0.49 \pm 0.09, \mathrm{P}=0.1635)$.

Similarly, the mean density of large saplings did not vary significantly between canopy gaps and intact forest transects (mean large sapling density $\pm 95 \% \mathrm{CI}=$ gap density: 0.42 \pm 0.06 , transect density: $0.43 \pm 0.12, \mathrm{P}=0.3983)$. 


\subsection{Relative successional status of gap understory saplings and overstory trees}

ISAs of small and large saplings found in the gaps were compared with those based on canopy trees. The actual canopy ages were closely correlated with the ISAs, $\mathrm{R}^{2}$ $=0.804$ (Figure 18). Comparing small saplings to the canopy, two-way ANOVA indicated that the interaction between saplings/trees and the forest age class was significant $(\mathrm{P}<0.05)$ (Table 4, Figure 19). Small gap saplings and trees varied significantly ( $\mathrm{P}<0.0001)$, as did age classes $(\mathrm{P}<0.0001)$ (Table 4). The sapling ISAs were greater than the canopy. The greatest difference was between ISAs of young forest saplings and trees; this difference decreased with increasing forest age (Figure 19).

Comparing large saplings to the canopy, two-way ANOVA indicated that the interaction between saplings/trees and the forest age class was significant $(\mathrm{P}<0.01)$ (Table 4, Figure 19). Large saplings and trees varied significantly $(\mathrm{P}<0.0001)$, as did age classes $(\mathrm{P}<0.0001)$ (Table 4). Like small saplings, the greatest difference was between ISAs of young forest saplings and trees; this difference decreased with increasing forest age (Figure 19).

In canopy gaps, both small and large saplings presented similar ISAs in young and middle age forests, but increased in mature forests. The canopy layer showed a linear increase in ISA across age classes, presenting the largest difference in ISAs in the young forests. 


\subsection{Relative successional status of gap and transect saplings}

Small and large sapling ISAs were compared between canopy gaps transects in the undisturbed forest. Comparing small saplings in gaps to transects, two-way ANOVA indicated that the interaction between gap/transect saplings and the forest age class was significant $(\mathrm{P}<0.05)$ (Figure 20). The difference was significant across age classes $(\mathrm{P}<$ 0.005) but not between gap and transect saplings $(\mathrm{P}=0.4492)$ (Table 4$)$. In young forests, gap saplings had higher ISAs, but in middle age gaps transects had slightly higher ISAs. In mature forests, the gap and transect ISAs were similar.

Comparing large saplings in gaps to transects, two-way ANOVA indicated that the interaction between gap/transect saplings and the forest age class was not significant $(\mathrm{P}=0.0538)$. However, large saplings in gaps had significantly higher ISAs than in

transects $(\mathrm{P}<0.005)$ (Table 4). Across gaps and transects, the ISAs showed a significant linear increase with increasing age class $(\mathrm{P}<0.001)$ (Table 4$)$.

\subsection{Forest overstory density}

Mean canopy gap overstory density increased with increasing stand age (mature: 76.77\%, middle aged: 72.29\%, young: 66.84\%) (Figure 21). Two-way ANOVA indicated overstory density varied significantly across forest age classes, decreasing over time $(\mathrm{P}<0.05)$. Overstory density was similar in all gap sizes, (small: 71.64\%, medium: 71.44\%, large: $72.82 \%)$ and there was no significant difference $(\mathrm{P}=0.8941)$ (Figure 22). The forest age-by-gap size interaction was not significant $(\mathrm{P}=0.3204)$. 


\section{DISCUSSION}

\subsection{Canopy gap identification and scouting}

The method of using a LiDAR model to identify canopy gaps appears to be suited primarily for identifying gaps in natural areas of the forest without major anthropogenic debris. Major modifications such as remnant buildings, concrete foundations, abandoned roads, and large stone piles produce alterations to the canopy structure significant enough to be seen in the LiDAR canopy model decades later. This model would not likely be

effective for identification of canopy gaps in Miami's hardwood hammock city parks. As part of the urban matrix, past and present infrastructure most likely defines the contours of the canopy to an extent where these shapes are unsuitable for study of natural canopy gap dynamics. For example, Kendall Indian Hammocks Park in Southwest Miami-Dade County is shaped by an electrical substation, walking trails, a waste management facility, and the movements of a fleet of government vehicles stationed there. LiDAR would not be useful for identifying canopy gaps in this park.

\subsection{Canopy gap distribution}

At $1.05 \%$, the young forest had three times as much of the forest in a gap phase than middle age and mature forest combined. While this figure may represent a slightly greater distribution of unnatural gaps, stemming from more recent and more extreme anthropogenic disturbance in young forests, there may be biological origins for this 
skewed distribution of gaps. As pioneer species all begin growing at the same time following land abandonment, they create a cohort of individuals of the same age and possibly physiological constitution (Mueller-Dombois 1983). Because members of this cohort are the same age, they may begin to senesce at approximately the same time. Even if they are not biologically senescing, they may all reach similar allometric characteristics at nearly the same time, such as a mechanical imbalance rendering the trees top heavy and vulnerable to wind disturbance (Franklin et al. 1987). This wave of mortality from the death of many pioneer trees may introduce the development of a new cohort. With each generation of species turnover, the cohort sizes would be expected to be smaller and increasingly irregular (Mueller-Dombois 1983). The LiDAR data, collected in early 2008, may have captured a specific period in time where large-scale mortality was occurring across a cohort of trees in early successional forests. LiDAR data collected in the future may show waves of mortality among later successional cohorts, although these may be smaller.

\subsection{Sapling densities across age and size classes}

With increasing stand age, mean canopy gap sapling density per square meter increased significantly. This may indicate a biological difference between species growing in different gap environments. Late-successional species may have life history traits better suited for the gap environment, allowing them to grow at higher densities under gap conditions.

A slight decrease in sapling density was seen with increasing canopy gap size, which was not statistically significant. It is possible that a significant difference could be 
observed by examining larger canopy gaps. Larger gaps do not occur in this forest, most likely due to the small stature of trees in a heavily hurricane and wind impacted forest. In North Key Largo, the canopy has a median height of 12.70 meters, as calculated from the LiDAR DCM. This is much smaller than canopies of many other forest types (Canham et al. 1990). Canopy gaps large enough to show a significant decrease in sapling density may not exist in this forest.

\subsection{Comparison of sapling densities between canopy gaps and intact forest transects}

The densities of all sapling sizes did not vary significantly between canopy gaps and intact forest transects. Similarly, there was no significant difference between small saplings or large saplings. Without taking species composition into consideration, in this forest there does not appear to be a difference in suitability of canopy gaps or intact forest to tree saplings. It is possible the small stature of these dying trees and the small gaps resulting from their treefalls do not create enough spatial heterogeneity to alter the densities of saplings compared to the intact forests.

\subsection{Relative successional status of gap understory saplings and overstory trees}

In canopy gaps, ISAs for small and large canopy saplings were similar. Both small and large saplings presented similar ISAs in young and middle age forests, but increased in mature forests. The canopy layer showed a linear increase in ISA across age classes, presenting the largest difference in ISAs in the young forests (Figure 19). The 
ISA appears to advance in the gaps to the point where further progress is no longer possible.

The greatest difference between gap saplings and the canopy was in young forests. In this situation, the young gap saplings increase the ISAs all the way to the canopy ISA of mature forests, providing a shortcut to maturity.

The large saplings consistently showed a slightly higher ISA in the canopy gaps than the small saplings. In Barro Colorado Island in Panama, pioneer tree species showed low survival rates in gap conditions (Welden et al. 1991). A lower rate of survival in pioneer species could leave larger saplings to represent a higher ISA than their smaller, presumably younger counterparts. Seedling and sapling mortality was recorded as being higher for smaller individuals in a tropical dry forest in Ghana (Swaine, Lieberman, and Hall 1990). High mortality of seedling suggest that selection pressures should be especially strong on saplings in the gaps, and that ill suited species would be less likely to survive long term (Denslow 1980a). Seeds may be able to arrive and establish in suboptimal conditions, but differential mortality may lead to the species composition observed in larger saplings (Engelbrecht et al. 2007). As the saplings that survive to larger sizes in the canopy gaps are more late-successional species, they may have life-history trails better suited for long term survival in these forests. The survey conducted in this study of saplings is a snapshot of growth in the forest. The larger saplings have already grown beyond the height of the smaller saplings, and presumably some individuals succumbed to herbivory, disease, fatal resource suppression, or other causes of mortality. Differential mortality should continue to remove individuals of species ill-suited for the particular microenvironment. If the same saplings were 
followed decades later, the difference in ISAs based on these trees could be even greater in the gaps, when the pioneer species saplings have died and only late-successional trees have reached the canopy.

\subsection{Relative successional status of gap and transect saplings}

ISAs were compared between small and large saplings in the gaps and intact forest transects. In young forests small saplings in gaps presented a higher ISA than in transects, but this trend was reversed for middle age forest. By forest maturity, the sapling ISAs had equalized. Comparing large saplings, the ISAs were higher in gaps than transects in all forest, but the effect was greatest in young forests.

Considering the greater increase in ISA in young forest gaps, these gaps could represent a shortcut to forest maturity. Saplings all across the forest, in gap phase and undisturbed forest alike, showed a higher ISA than the canopy above. However, in young forest gaps, there is the largest change in sapling composition, with a mean ISA increasing nearly three decades. The young forests also have the highest percentage of area in a gap phase, resulting in a larger portion of the young forest experiencing rapid succession. In addition, these gaps could provide a seed source for short-distance seed dispersal for succession in the young forest understory. Long-distance dispersal of mature species seeds from across the island (or from further away), into canopy gaps, could be facilitated by birds, while short distance dispersal may be facilitated by mammals. 


\subsection{Forest overstory density}

Overstory density would be expected to decrease with increasing gap size, but the overstory densities were nearly identical among all gap sizes with no significant difference. The densiometer does not measure overstory density directly above the recorder; it takes in much of the surrounding canopy. Overstory density would still be expected to decrease in gaps larger than those present in Key Largo, but larger gaps were not available to sample. Overstory density did increase significantly with increasing gap age. The gaps were sampled towards the end of the South Florida dry season, and some deciduous trees did not have full canopies of leaves, such as B. simaruba and $P$. piscipula. These species are more prevalent in early successional forests (Table 1).

\subsection{Trees forming canopy gaps}

The five most common tree species identified forming canopy gaps, $L$. bahamensis, C. diversifolia, B. simaruba, M. toxiferum, and P. piscipula, were also the five most common canopy tree species in Key Largo near to the gaps (Figure 23). The order of most common canopy species was the same as forming treefall gaps, except that fourth ranked L. bahamensis was the most common gap former, with more than twice as many L. bahamensis identified forming gaps than any other species. The high representation of $L$. bahamensis could result from multiple factors. This early successional pioneer often forms wide upper canopies and the resulting treefall can create a disproportionately large opening in the canopy, usually large enough to be visible on the LiDAR canopy model. It is also possible that some of the unique features of the tree, 
such as its light, exceptionally smooth bark, allow for identification longer after death than some other species. The same could be said for B. simaruba, which has shaggy, peeling bark that remains distinctive in the early stages of decomposition.

Many canopy gaps consisted of multiple trees, with a mean of 2.89 trees per canopy gap. The presence of multiple treefalls in a gap may be an important ecological process, increasing the total area of the gap. The gap formation process may also be slowed by the proximity of other trees, if a tree has uprooted and is being supported by another tree, it may take additional time before the tree falls and the saplings below are fully released from light suppression. The falling of trees can kill other, potentially healthy trees. More than $15 \%$ of tree mortalities in medium and old growth Pacific Northwest Douglas-fir forest were caused by the falling of neighboring trees (Franklin et al. 1987). The large-scale senescence and death among cohorts of early successional trees in Key Largo could result in numerous multiple-treefall gaps, increasing the percentage of gap area across the age class.

The connectivity of trees in this forest may result in smaller gap sizes and fewer trees per gap in Key Largo than in tropical rainforests. Across the wet tropics, dense woody vines forming tree-climbing lianas are a common occurrence. These vines may create a strong connection between trees, so that a treefall may create a chain reaction pulling down numerous trees simultaneously. In rainforests, lianas were attributed as a cause of the largest canopy gaps (Denslow 1980a). 


\subsection{Soil and water factors in canopy gap succession}

Other factors, such as soil and fresh water availability, may influence tree species regeneration in Key Largo. Niche differentiation based on soil water availability has been shown to be a direct determinant to tropical tree species distribution on a local site scale (Engelbrecht et al. 2007). Several observations in the field suggest that the formation of soil, and the resulting capacity of freshwater storage, may be involved in the successional sequence of the forest. In the southern part of the island, there are abandoned building projects, with barren concrete foundations. Growing directly on top of these foundations, with effectively no soil, were pioneer species like $P$. piscipula and S. mahogani (personal observation). In areas recovering from a mid 1970s forest fire, the soil layer was still partially depleted. Some of the limited soil was composed of the stillidentifiable leaf litter of $L$. bahamensis, although other leaf litter did appear to be forming a thin soil layer with a patchy distribution, deeper in lower areas between higher bedrock outcroppings. Most of the trees were pioneer species, growing from these soil pockets (personal observation). In the low elevation ecotone, where hardwood hammock transitions to buttonwood and eventually a mangrove ecosystem, the forest is composed of pioneers like $P$. piscipula and $M$. toxiferum, regardless of the age of the forest (personal observation). As the elevation declines, the availability of fresh water should similarly be reduced. Finally, in abandoned, unpaved roads, regardless of the age of surrounding forest, the new trees which begin forming on the road are usually pioneers such as B. ovata (personal observation). These forest roads can result in soil compaction and reduced porosity and water infiltration (Elseroad, Fulé, and Covington 2003). 
In each of these cases, the quantity of freshwater available for trees may be reduced compared to other areas of the forest. The young forests observable now in Key Largo contain canopy gaps with saplings that are late-successional, rapidly advancing the ISA. It is possible that by the current stage even of young forests that the soil conditions have changed to be more hospitable to mature species, possibly by increased capacity for water storage. Growing on top of concrete foundations, the roots of pioneer trees may crush and raise the concrete, exposing the soil below, or the above-ground roots may support accretion of soil directly on top of the foundations. In abandoned roads, pioneer root growth may loosen the soil, increasing pore space and allowing for future growth of later successional species. In the burned areas, soil did already appear to be forming decades after the forest fire. This disturbance may have removed much more soil than the agricultural activities elsewhere on the island, and a more prolonged recovery may be necessary for succession. The low elevation ecotone would not be expected to support succession to mature forest. In this zone, freshwater availability is limited not by the storage capacity of soil, but by the influence of saltwater. This region should actually expand in the coming decades as a result of sea level rise.

Forest soil depths were recorded in Key Largo in the same age class divisions. Soil depth increased with successional age of the forest, from a mean of $12.3 \mathrm{~cm}$ in young forests to $16.7 \mathrm{~cm}$ in mature forest, an increase of over one third across age classes (Barth, unpublished data). The differences in soil depth may be a critical factor in determining the best competitor in the particular microenvironment.

Canopy gaps should in play a key role in soil development, particularly due to the high rate of decomposition and organic matter turnover in Florida Keys forests. The 
formation of a canopy gap necessarily involves the deposition of a large quantity of organic matter. In the Florida Keys, measured litter decomposition ranged from 18-52\% within one year, 30-62\% over two years (Ross, Coultas, and Hseih 2003). Canopy gaps in Key Largo were not studied until at least six years after formation. In Costa Rican canopy gaps, nutrient availability was higher in canopy gaps than surrounding forest, with the hypothesized cause being the decomposition and mineralization of treefall litter (Denslow, Ellison, and Sanford 1998). In the crown-fall zone, nitrate and phosphate levels were highest, while lower levels were recorded in the root-throw zone and along the trunk of the fallen tree (Vitousek and Denslow 1986). The high turnover rate of leaf litter in Key Largo may not result in greater soil depth from leaf litter, but the decomposition of wood may contribute more soil to the gap environment. The canopy gaps should have deeper soils and more nutrients than adjacent forest, which may be better able to support late successional species. The effect would be most profound in young forests with thinner soils, where the increase in soil layer in a canopy gap would provide a greater percent increase in soil depth relative to the surrounding forest. The availability of soil water has been demonstrated to influence the growth of seedlings in a canopy gap. Two oak species transplanted to canopy gaps showed three times as much growth during a drought period compared to individuals transplanted in non-gap phase forest (Rodríguez-Calcerrada et al. 2007). This difference was attributed to a reduction in competition for water below ground in the canopy gaps. In Costa Rica, the fine root dry mass decreased significantly compared to the surrounding forest (Denslow, Ellison, and Sanford 1998). The death of a canopy tree in any environment reduces the competition 
for water in the gap that the tree once occupied. The interaction of soil and water in canopy gaps may be providing a pathway for the growth of mature forest species.

The increase in soil, water, and nutrient availability to late-successional species may be the reason that Hurricane Andrew appeared to advance, rather than restart, the successional sequence (Ross et al. 2001, Carrington et al., unpublished manuscript). The hurricane disturbance may provide light conditions that would otherwise favor pioneer species, but the change in soil conditions may favor mature species, as the biomass turnover development of soil and release of nutrients. This effect could be reversed if the hurricane storm surge could wash away a significant portion of the hammock soil or raise salinity to levels intolerable to mature species.

The differences in pioneer and mature species soil and fresh water requirements may relate to leaf phenology. Pioneer species in this environment are primarily drought deciduous, while the mature species are evergreen (Ross et al. 2001). If the late successional species require more water year round, they may not survive in soil conditions that are unable to store the small amount of fresh water that falls in the South Florida dry season. Conversely, the pioneer species may be better suited to capitalize on the rainy season water availability, with less dependence on the soil to provide water the rest of the year. 


\section{CONCLUSION}

The canopy gaps in Key Largo provided the greatest change in ISA in young forest canopy gaps. This category also featured the largest ISA increase relative to saplings growing in intact forest. The cause of this increase is hypothesized to be the interaction of soil, light, and fresh water factors.

The development and characteristics of soil in canopy gaps may be the critical factor. Soil depth in Key Largo increased across age classes of the forest (Barth, unpublished data). A litter turnover rate of $30-62 \%$ over two years would indicate that by the time these gaps were studied, much organic matter had decomposed and bolstered the canopy gap soil layer (Ross, Coultas, and Hsieh 2003). In a young forest with thinner soil, this increase in gap soil would create the largest relative increase in soil depth. It could also provide a critical increase in nutrients resulting in rapid sapling growth (Denslow, Ellison, and Sanford 1998). Due to an increase in the capacity for thicker soil to retain fresh water, and reduced below ground water competition, a young forest gap may favor the development of late-successional, evergreen tree species with greater year-round water requirements.

The interaction of these soil water factors with the light environment of the gap can determine the composition and density of regenerating trees. Saplings in Key Largo exist throughout the forest at the same densities in gaps as well as intact forest. However, in young forests gaps the species composition produces a higher inferred stand age than in the intact forest. This indicates that the gap opening corresponds with some mortality 
among the earlier successional species of the gap, and corresponds with increased survival or recruitment of later successional species saplings into the gap. The percent of forest overstory density in the gap also increases with the age of the forest, and this will correspond with a decrease in light availability, possibly depriving pioneer saplings of their light requirements.

Canopy gaps in many forests are thought of as resetting the successional sequence, allowing for pioneer species to colonize the gap and recreate an early successional environment on a small scale (Ricklefs 1977, Whitmore 1989). Whitmore (1989) splits trees into two groups based on their germination requirements, where pioneer species need large gaps to germinate in the open, and in small gaps seedlings that became established in the shade of the closed forest are released from suppression. In Costa Rica, large canopy gaps initially provided roughly double the light availability of small canopy gaps (Denslow, Ellison, and Sanford 1998). Neither Denslow et al. nor Whitmore define sizes of small and large gaps, but it is possible that none of the gaps in North Key Largo are large enough to qualify for pioneer reestablishment. Even in South Florida mangrove forests, the smallest lightning-formed gaps were similar in size to the largest hardwood hammock gaps, and the largest mangrove gaps were three times larger than the largest hardwood hammock gaps (Zhang et al. 2008). The small size of Key Largo hardwood hammock gaps may allow enough light to promote sapling growth, without enough light to accelerate soil desiccation, promoting the survival of the potentially hydrophilic mature species. There was no difference in overstory density and thus light availability across gap size classes in Key Largo. 
The short statures of hardwood hammock trees are shaped by the selection pressure of hurricanes, and taller trees were the most likely to fall and die in Hurricane Andrew (Duryea et al. 1996). Australian pines, a category one invasive species in Florida, grow considerably taller than the native hammock vegetation, and within the urban matrix of Miami, a homeowner survey reported only $4 \%$ of Australian pines remained standing following Hurricane Andrew (Duryea et al. 1996). The increase in soil, water, and nutrient availability to late-successional species may be the reason that Hurricane Andrew appeared to advance, rather than restart, the successional sequence (Ross et al. 2001, Carrington et al., unpublished manuscript). The hurricane disturbance may provide light conditions that would otherwise favor pioneer species, but the change in soil conditions may favor mature species.

The increase in inferred stand age in young forest gaps is particularly interesting as it relates to the distribution of canopy gaps. The young forest featured greater numbers of canopy gaps, larger canopy gaps, and the highest percent of forest area in a gap phase. In the young forests, these gaps may represent individual rapid points of succession, which could serve as a short-distance seed source for understory succession in the surrounding forest. Long-distance dispersal of mature species seeds from across the island (or from further away), into canopy gaps, could be facilitated by birds, while short distance dispersal may be facilitated by mammals.

The reset of successional sequence in Florida Keys tropical hardwood forests may require more than canopy gaps or typical hurricane disturbance. This sets the role of canopy gaps apart in this forest compared to many other forested ecosystems. A 
complete successional reset may require the depletion of the soil layer by fire, intensive agriculture, or unusually intense hurricane disturbance. 


\section{TABLES}

Table 1: Cause of gaps in each gap size class

\begin{tabular}{|llllll|}
\hline Gap size & Treefall & Fire & Manmade & Solution Hole & Unknown \\
\hline Small $(20-28$ sq m) & 11 & 1 & 3 & 0 & 0 \\
Medium (28-50 sq m) & 6 & 3 & 4 & 2 & 0 \\
Large (50+ sq m) & 8 & 0 & 4 & 2 & 1 \\
\hline
\end{tabular}

Causes of gaps from initial scouting, arranged by small, medium, and large gap sizes. Small gaps had the largest proportion of natural treefall gaps.

Table 2: Cause of canopy gaps in each forest age class

\begin{tabular}{|llllll|}
\hline Forest age & Treefall & Fire & Manmade & Solution Hole & Unknown \\
\hline Young & 5 & 4 & 4 & 2 & 0 \\
Middle Age & 11 & 0 & 4 & 0 & 0 \\
Mature & 9 & 0 & 3 & 2 & 1 \\
\hline
\end{tabular}

Cause of canopy gaps across age classes. Middle age gaps had the highest proportion of natural treefall gaps. All fire gaps were in young forests. Mature and young forests both had solution holes that appeared as canopy gaps on the LiDAR model. 
Table 3: Canopy gap successional age optima

\begin{tabular}{|c|c|c|c|}
\hline Name & Count & Optimum & Tolerance \\
\hline Randia aculeata & 1 & 21 & 30.5 \\
\hline Zanthoxylum fagara & 1 & 33 & 30.5 \\
\hline Hibiscus tiliaceus & 1 & 38 & 30.5 \\
\hline Lysiloma bahamensis & 13 & 47.7 & 24.7 \\
\hline Eugenia axillaris & 11 & 56.7 & 29.1 \\
\hline Swietenia mahagoni & 15 & 58.1 & 24.1 \\
\hline Ficus citrifolia & 11 & 61.4 & 24.2 \\
\hline Colubrina elliptica & 6 & 62.4 & 36.9 \\
\hline Eugenia foetida & 6 & 62.7 & 18.6 \\
\hline Piscidia piscipula & 22 & 65.7 & 26 \\
\hline Bourreria ovata & 11 & 67.5 & 34.2 \\
\hline Metopium toxiferum & 24 & 68.6 & 28 \\
\hline Sideroxylon salicifolium & 19 & 69.2 & 30 \\
\hline Guettarda scabra & 3 & 69.3 & 21.5 \\
\hline Bursera simaruba & 25 & 70.2 & 25 \\
\hline Calyptranthes pallens & 1 & 73 & 30.5 \\
\hline Canella winterana & 1 & 73 & 30.5 \\
\hline Thrinax morrisii & 1 & 73 & 30.5 \\
\hline Ximenia americana & 3 & 73 & 30.5 \\
\hline Guapira discolor & 14 & 77.9 & 34.1 \\
\hline Guettarda elliptica & 8 & 79.4 & 30.6 \\
\hline Nectandra coriacea & 9 & 81 & 37.7 \\
\hline Exostema caribaeum & 1 & 83 & 30.5 \\
\hline Manilkara zapota & 1 & 83 & 30.5 \\
\hline Cocoloba diversifolia & 24 & 88.2 & 33.3 \\
\hline Drypetes diversifolia & 6 & 89.8 & 30.1 \\
\hline Amyris elemifera & 7 & 94.3 & 30 \\
\hline Sideroxylon foetidissimum & 4 & 95.1 & 36.7 \\
\hline Krugiodendron ferreum & 13 & 95.9 & 30.2 \\
\hline Ateramnus lucidus & 17 & 100.5 & 32.3 \\
\hline Pisonia aculeata & 2 & 109.4 & 56.6 \\
\hline Exothea paniculata & 7 & 110.7 & 33.2 \\
\hline Simarouba glauca & 5 & 121 & 39.6 \\
\hline Drypetes lateriflora & 3 & 130.5 & 14.8 \\
\hline Eugenia confusa & 1 & 133 & 30.5 \\
\hline Reynosia septentrionalis & 1 & 133 & 30.5 \\
\hline
\end{tabular}

Successional age optima, tolerances, and count of transects present for 35 Key Largo tree species from the survey of 45 canopy gaps. 
Table 4: ANOVA results for comparison of ISAs

\begin{tabular}{|llll|}
\hline & Degrees of freedom & F & P \\
\hline A & & & \\
Intercept & 1 & 1040.199 & 0.000000 \\
Age Class & 2 & 6.843 & 0.002027 \\
Population & 1 & 0.580 & 0.449162 \\
Age * Pop & 2 & 3.285 & 0.043834 \\
Error & 64 & & \\
\hline B & & & \\
Intercept & 1 & 689.3539 & 0.000000 \\
Age Class & 2 & 12.9058 & 0.000020 \\
Population & 1 & 27.6849 & 0.000002 \\
Age * Pop & 2 & 4.7335 & 0.012100 \\
Error & 64 & & \\
\hline C & & & \\
Intercept & 1 & 1109.987 & 0.000000 \\
Age Class & 2 & 8.310 & 0.000635 \\
Population & 1 & 12.012 & 0.000965 \\
Age * Pop & 2 & 3.065 & 0.053761 \\
Error & 62 & & \\
\hline D & & & \\
Intercept & 1 & 850.1182 & 0.000000 \\
Age Class & 2 & 15.2142 & 0.000004 \\
Population & 1 & 45.7575 & 0.000000 \\
Age * Pop & 2 & 5.6122 & 0.005752 \\
Error & 62 & & \\
\hline A OVA & & & \\
\hline
\end{tabular}

ANOVA for comparing ISAs of different groups. Age classes are young, middle, and mature. A: comparison of small saplings in gaps with small saplings in transects. B: comparison of small saplings in caps with the forest canopy. C: comparison of large saplings in gaps with large saplings in transects. D: comparison of large saplings in gaps with the forest canopy.

Table 5: Cause and geographic position of canopy gaps

\begin{tabular}{|llllll|}
\hline Geographic Position & Treefall & Fire & Manmade & Solution Hole & Unknown \\
\hline South & 5 & 0 & 8 & 0 & 1 \\
Central & 12 & 0 & 3 & 0 & 0 \\
North & 8 & 4 & 0 & 4 & 0 \\
\hline
\end{tabular}

Cause of canopy gaps from initial scouting, sorted by geographic position. Southern gaps are south 564345 E, 2785631 N. Northern gaps are north of 571231 E, 2796853 N. Central gaps are between these coordinates. Southern gaps are primarily manmade, and Northern gaps have a large portion of solution holes and fire-caused canopy gaps. Central gaps had the highest proportion of natural treefall gaps, and this area was selected for further study. 


\section{FIGURES}

\section{Study Area}

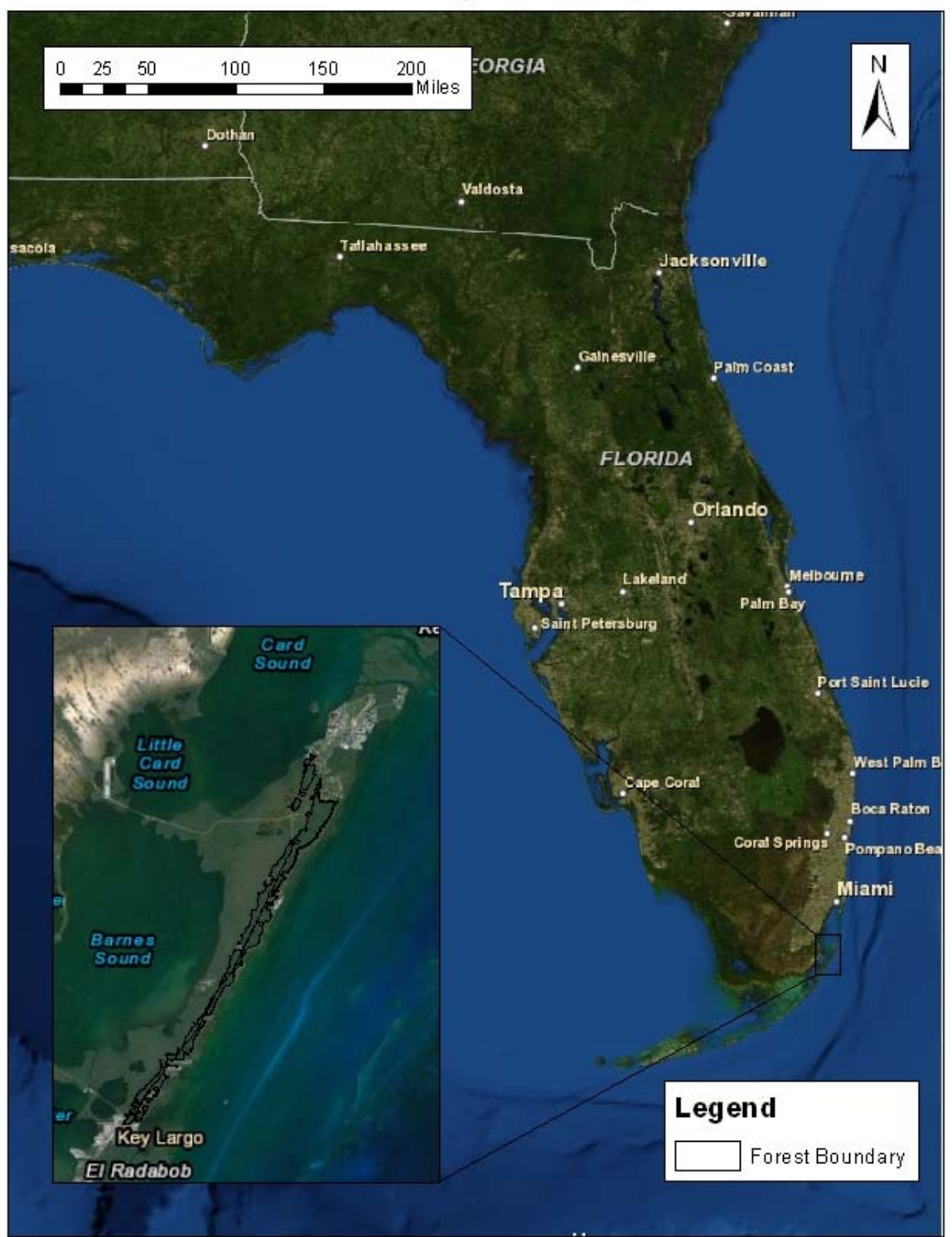

Figure 1: Location of study area

Location of the study area within the state of Florida. Key Largo is the northernmost island of the Florida Keys archipelago connected by the Overseas Highway. The boundary of the hardwood hammock forest is indicated by the black outline. 


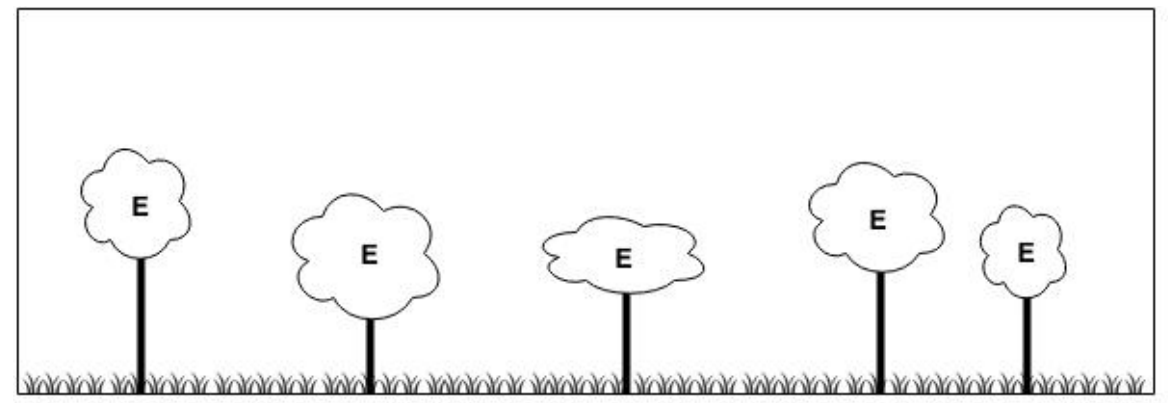

Following agricultural abandonment: a pioneer species begin to grow Note: Pineland habitat does not form due to insufficient fresh water $\mathrm{E}=$ Early successional species, $\mathrm{L}=$ Late successional species

$\forall=$ Ferns and shrubs

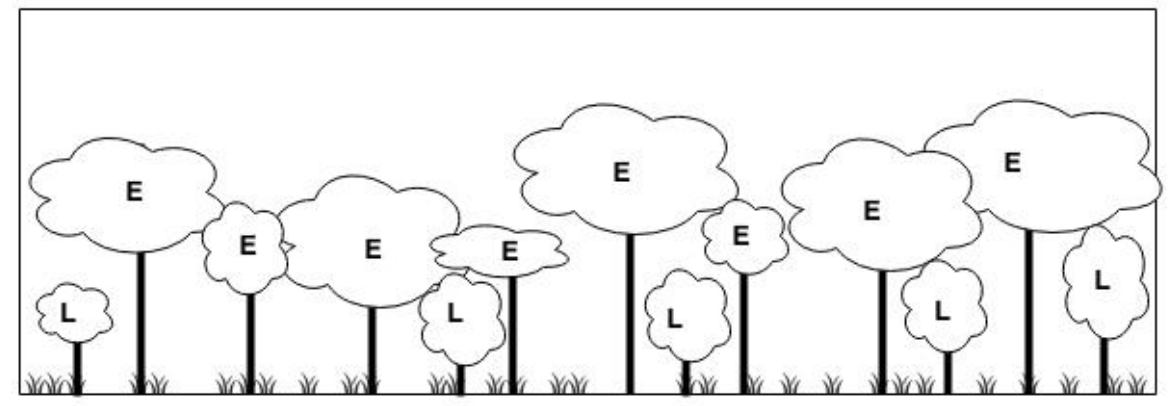

Next generation of saplings established, including late successional species, as the canopy closes $\mathrm{E}=$ Early successional species, $\mathrm{L}=$ Late successional species

$\forall \quad=$ Ferns and shrubs

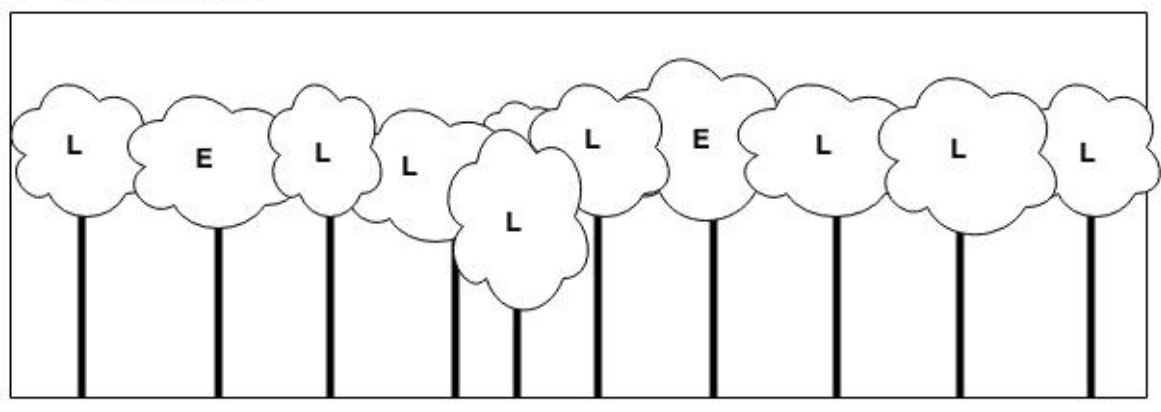

A mature forest is characterized primarily by late successional trees

$\mathrm{E}=$ Early successional species, $\mathrm{L}=$ Late successional species

Figure 2: Forest successional model.

Early successional pioneer species begin growing after agricultural abandonment. 


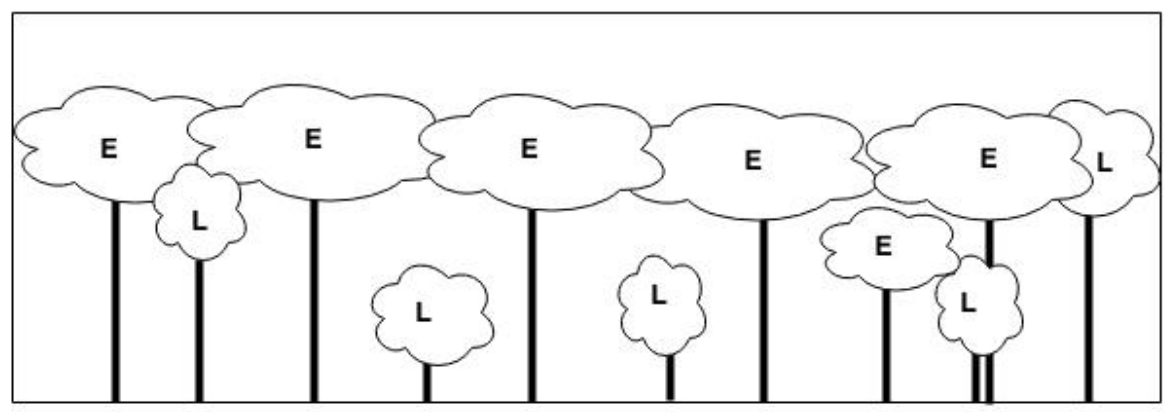

Many pioneer early successional species form very wide upper canopies

$\mathrm{E}=$ Early successional species, $\mathrm{L}=$ Late successional species

\& $=$ Canopy tree mortality

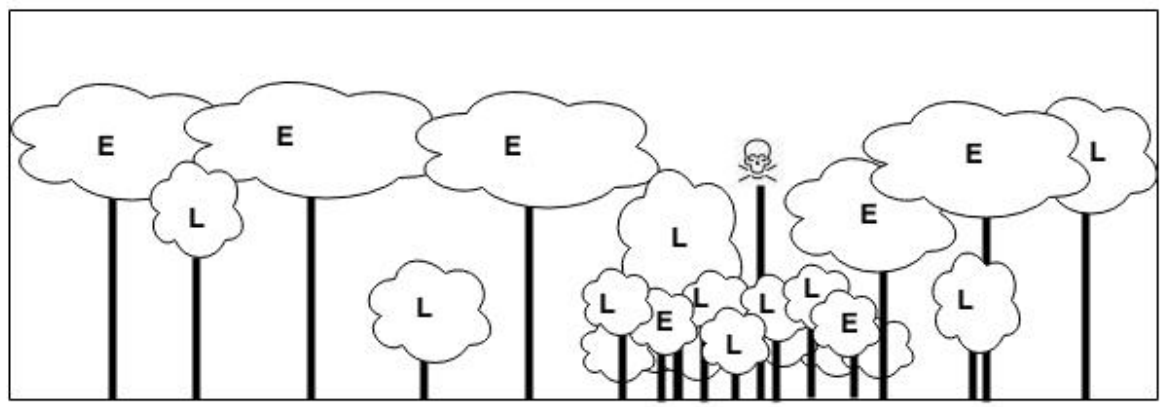

These large trees have high mortality in storms, and will create bigger canopy gaps than late successional trees $\mathrm{E}=$ Early successional species, $\mathrm{L}=$ Late successional species

se Canopy tree mortality

Figure 3: Early successional forest mortality model

Model of the mortality and larger gap size created by pioneer species with broad canopies, such as L. bahamensis. Cohort succession should also result in near-simultaneous death of multiple trees or stems, creating large, multi-tree gaps.

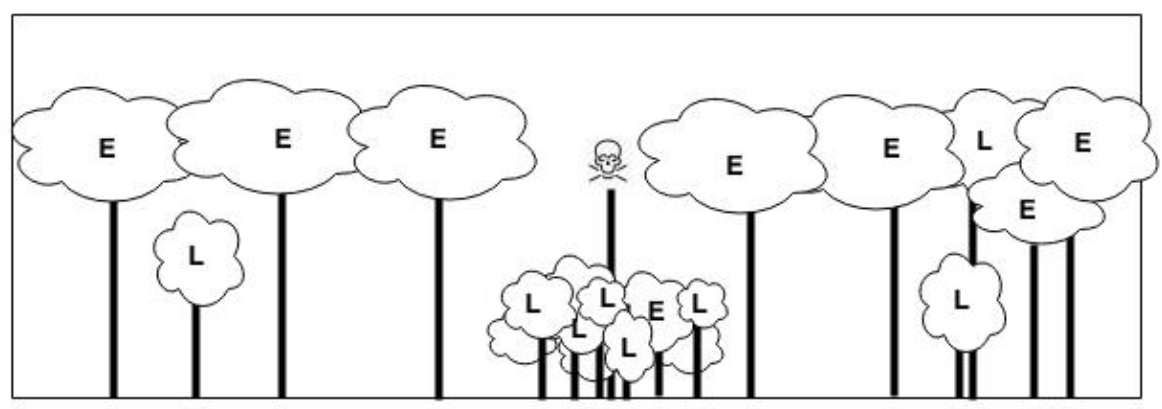

Canopy gaps allowing later successional species, increasing the ISA relative to the surrounding forest. $\mathrm{E}=$ Early successional species, $\mathrm{L}=$ Late successional species

= Canopy tree mortality

Figure 4: Canopy gap replacement model

Model of the replacement of a pioneer canopy through late successional saplings in a canopy gap. 


\section{Forest Age Map - Condensed Age Classes}

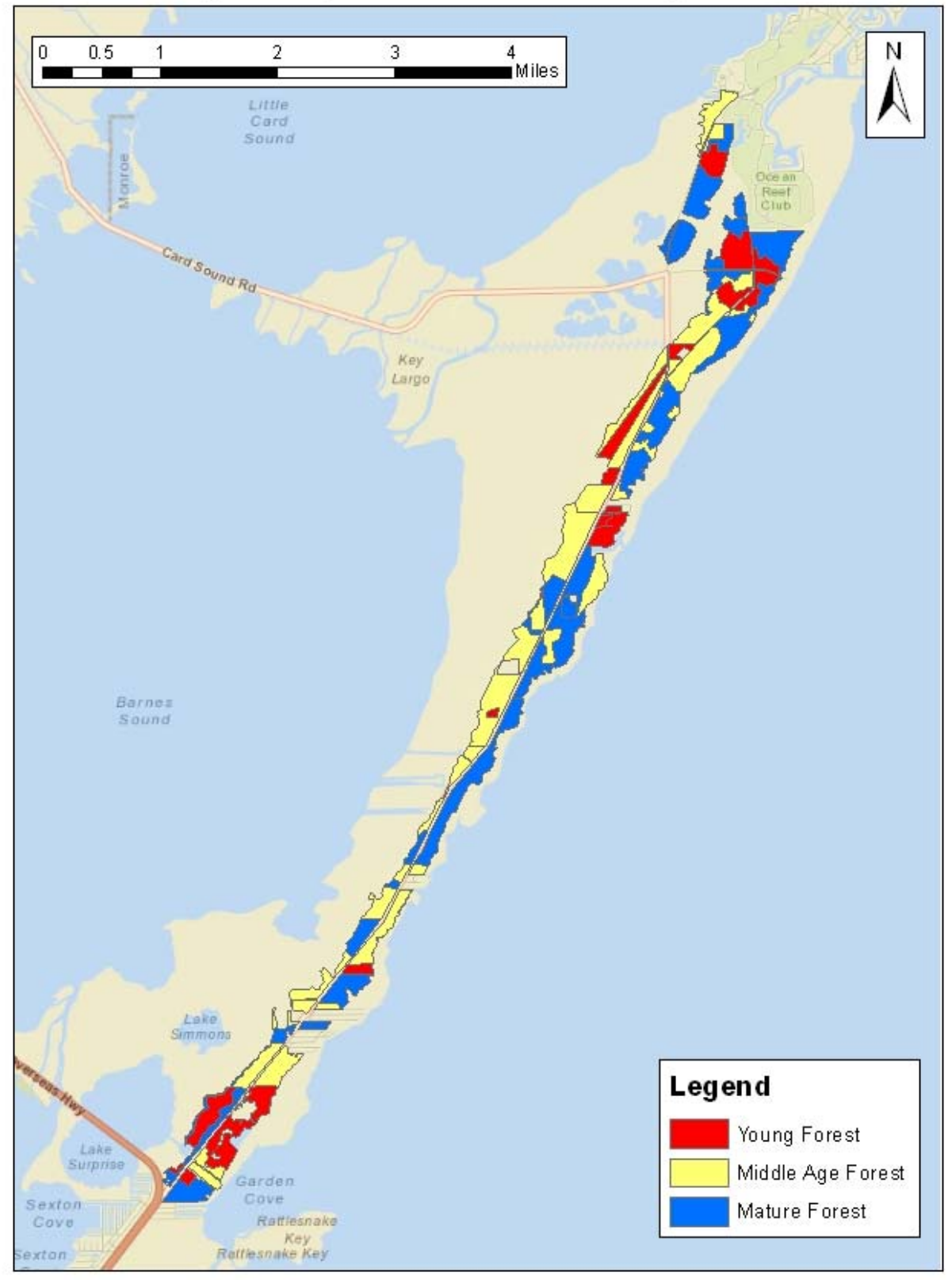

Figure 5: Condensed forest age map

Forest ages condensed into three classes for comparison of canopy gap species composition. Young forests are forests less than or equal to 43 years since clearing. Middle age forests are between 44 and 74 years old. Mature forests are at least 75 years old. 


\section{Forest Age Map}

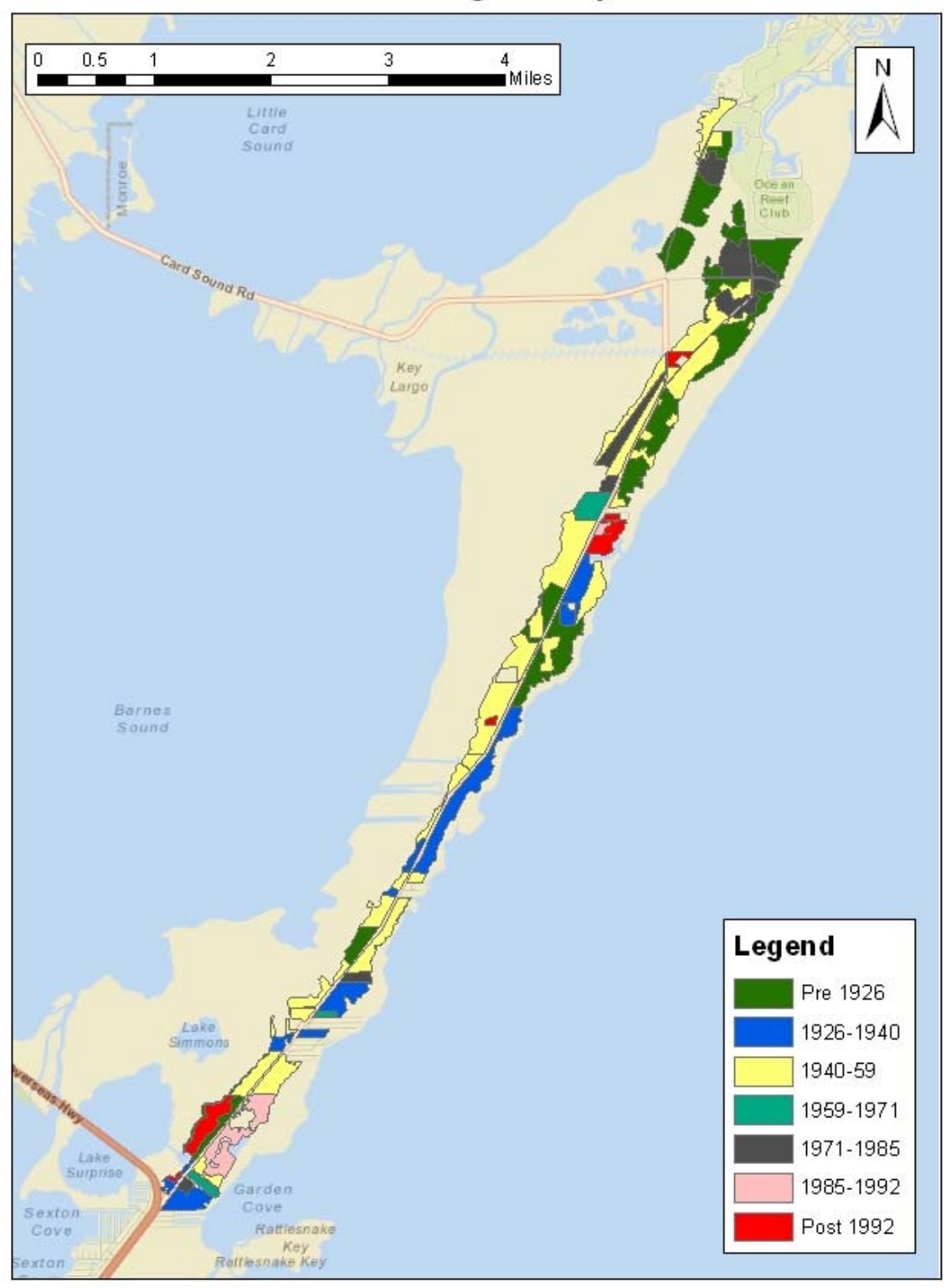

Figure 6: Forest age map

Forest ages were determined from time series of aerial photographs. Years indicated are years that forest growth was observed and has remained undisturbed by anthropogenic clearing. 


\section{Digital Elevation Model}

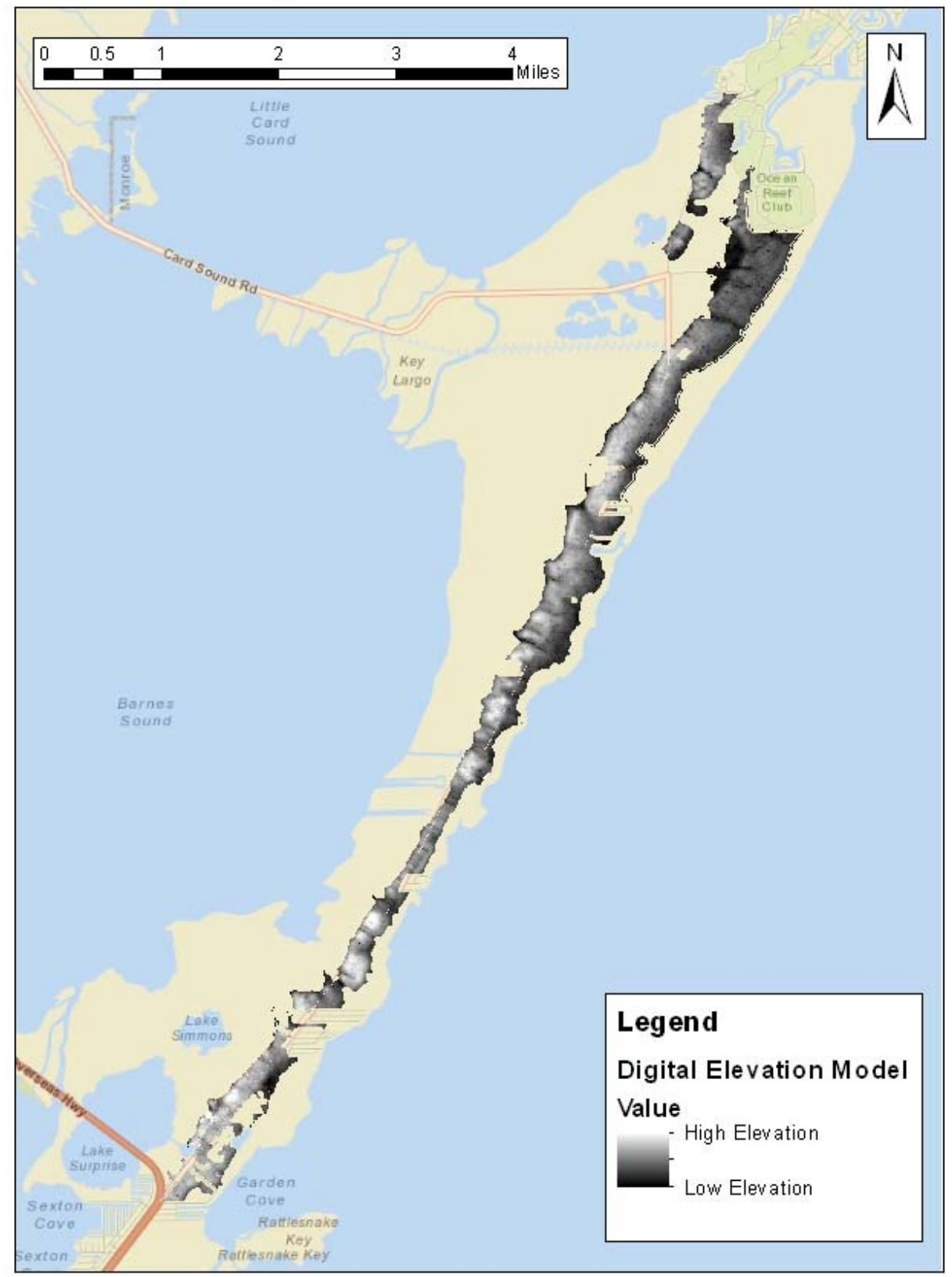

Figure 7: Digital elevation model 
Digital Elevation Model of the hardwood hammock forest within North Key Largo. Elevation indicated by grayscale, darker tones indicate lower elevation. This model shows the terrain elevation.

\section{Digital Surface Model}

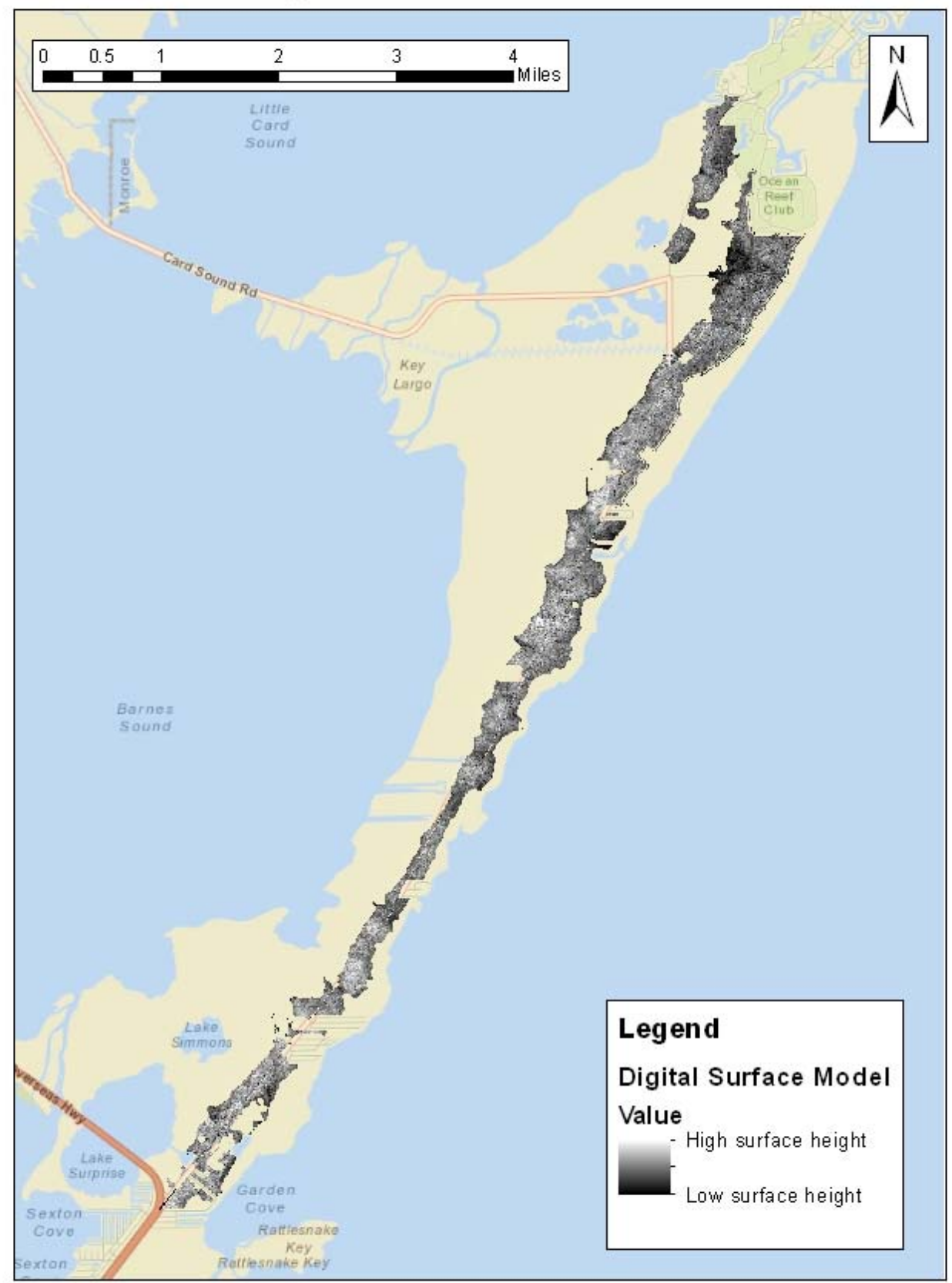

Figure 8: Digital surface model 
Digital Surface Model of the hardwood hammock forest within North Key Largo. Surface height indicated by grayscale, darker tones indicate lower surface height. This model shows the upper contours of the forest canopy, without correction for elevation.

\section{Digital Canopy Model}

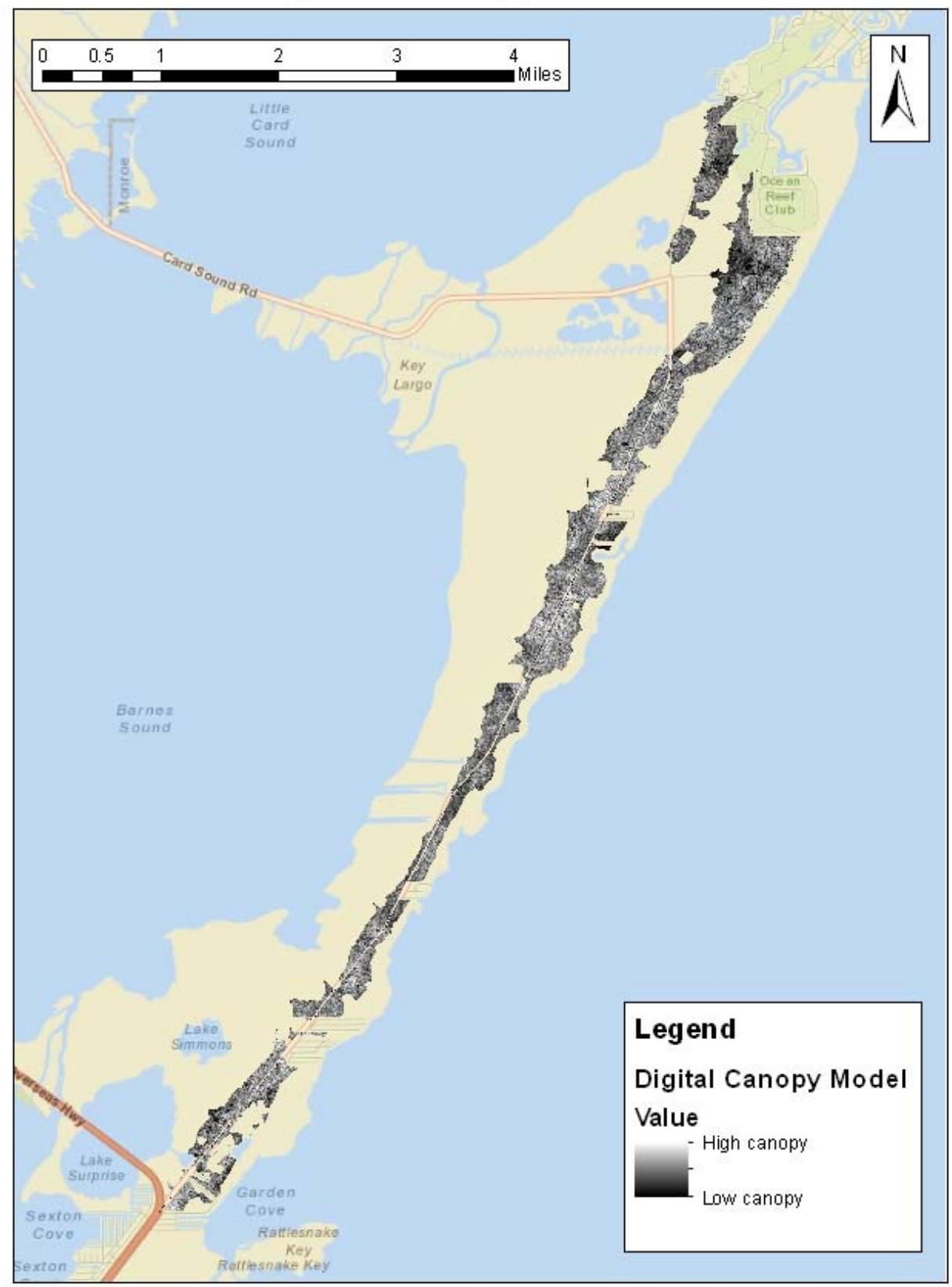

Figure 9: Digital canopy model 
Digital Canopy Model of the hardwood hammock forest within North Key Largo. This model subtracts the vertical difference between the DSM and the DEM, resulting in a model of tree canopy heights. Canopy height indicated in grayscale, with lower canopies indicated by darker tones.

\section{Neighborhood focal raster - Pixel size determination}

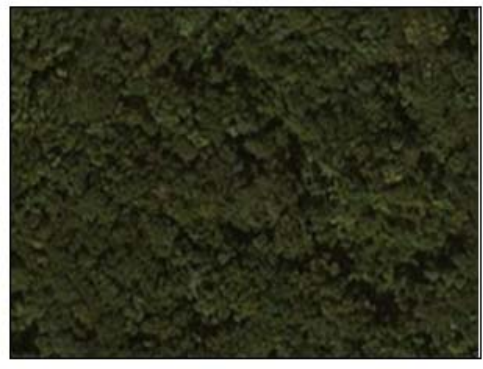

Forest imagery basemap

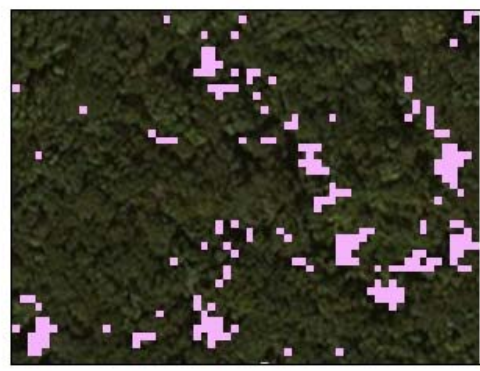

13 pixel neighborhood focal raster

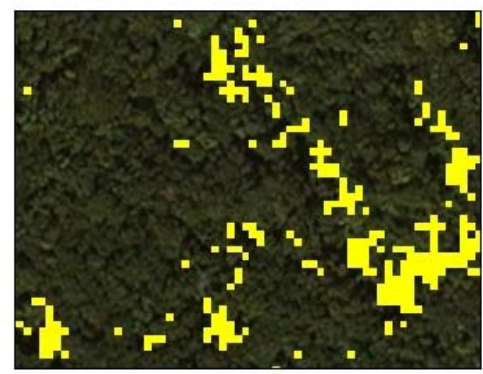

50 pixel neighborhood focal raster

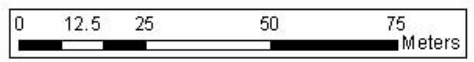

Figure 10: Neighborhood focal raster model

Determination of neighborhood focal raster pixel extent. Using a focal neighborhood smaller than 13 pixels (19.5 by 19.5 meters) misses most canopy gaps. Larger focal neighborhoods, such as 50 pixels, combined disconnected canopy gaps into larger continuous areas. 


\section{Existing Transects: $1994-2014$}

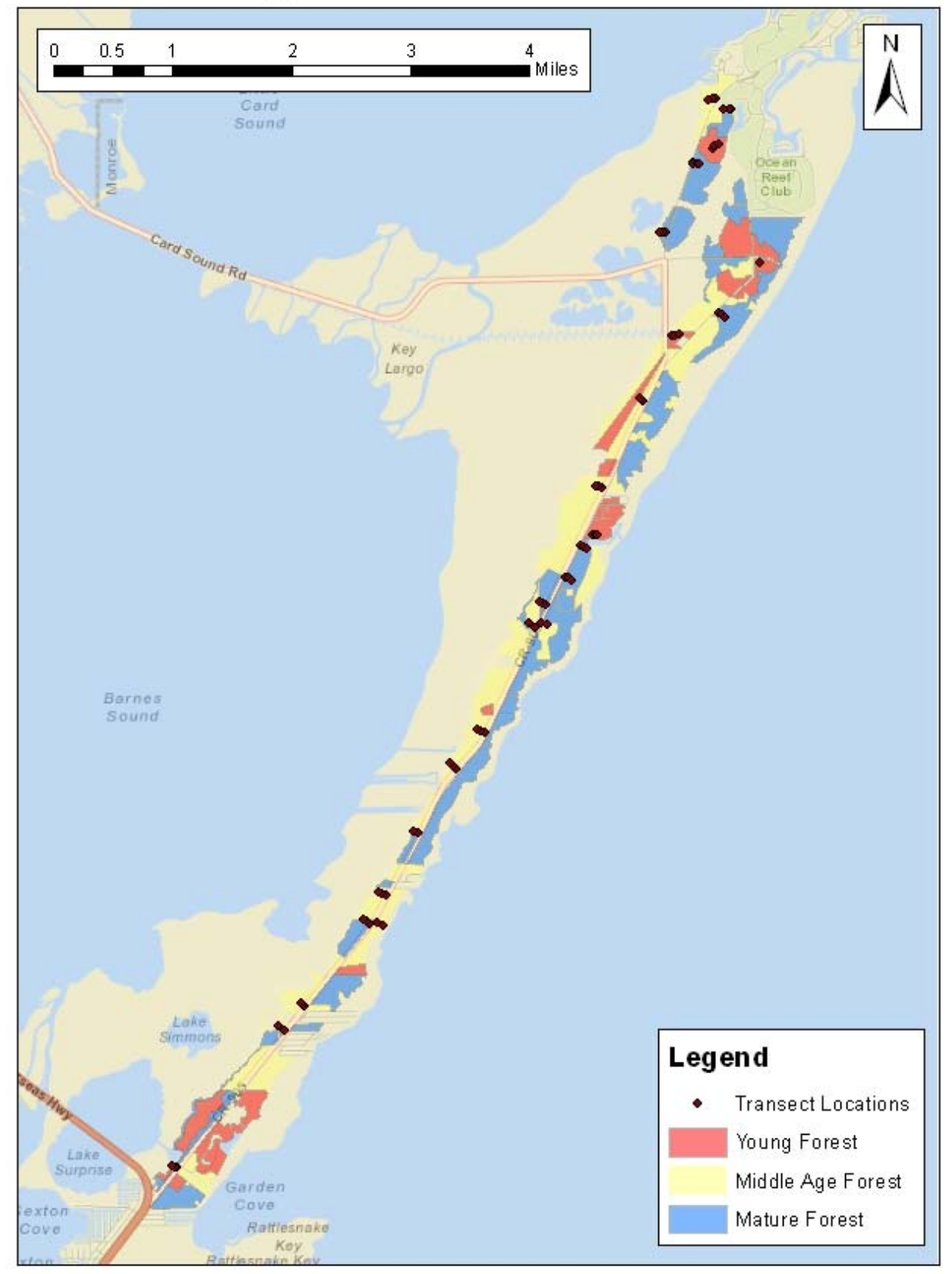

Figure 11: Forest transect locations

Location of existing forest transects, sampled between 1994 and 2014. Data from these transects have been used in Ross (2001) and Carrington et al. (unpublished manuscript). 


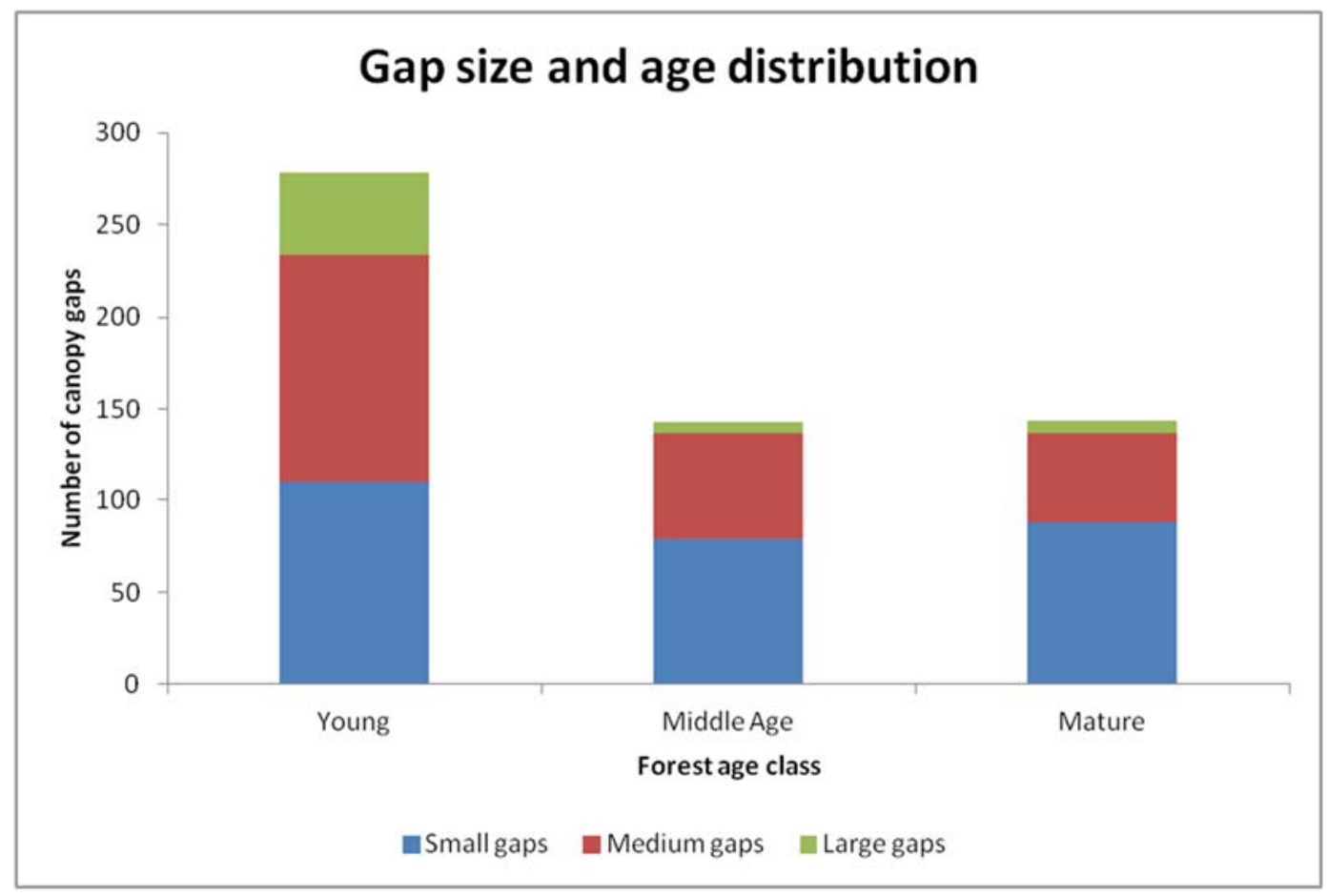

Figure 12: Distributions of age and size of forest canopy depression.

Young forests had almost as many canopy gaps as middle age and mature forests combined. The young forests also had the majority of all large canopy gaps, as well as more medium sized gaps. This resulted in young forests containing a larger percentage of gap phase area than the other age classes. 


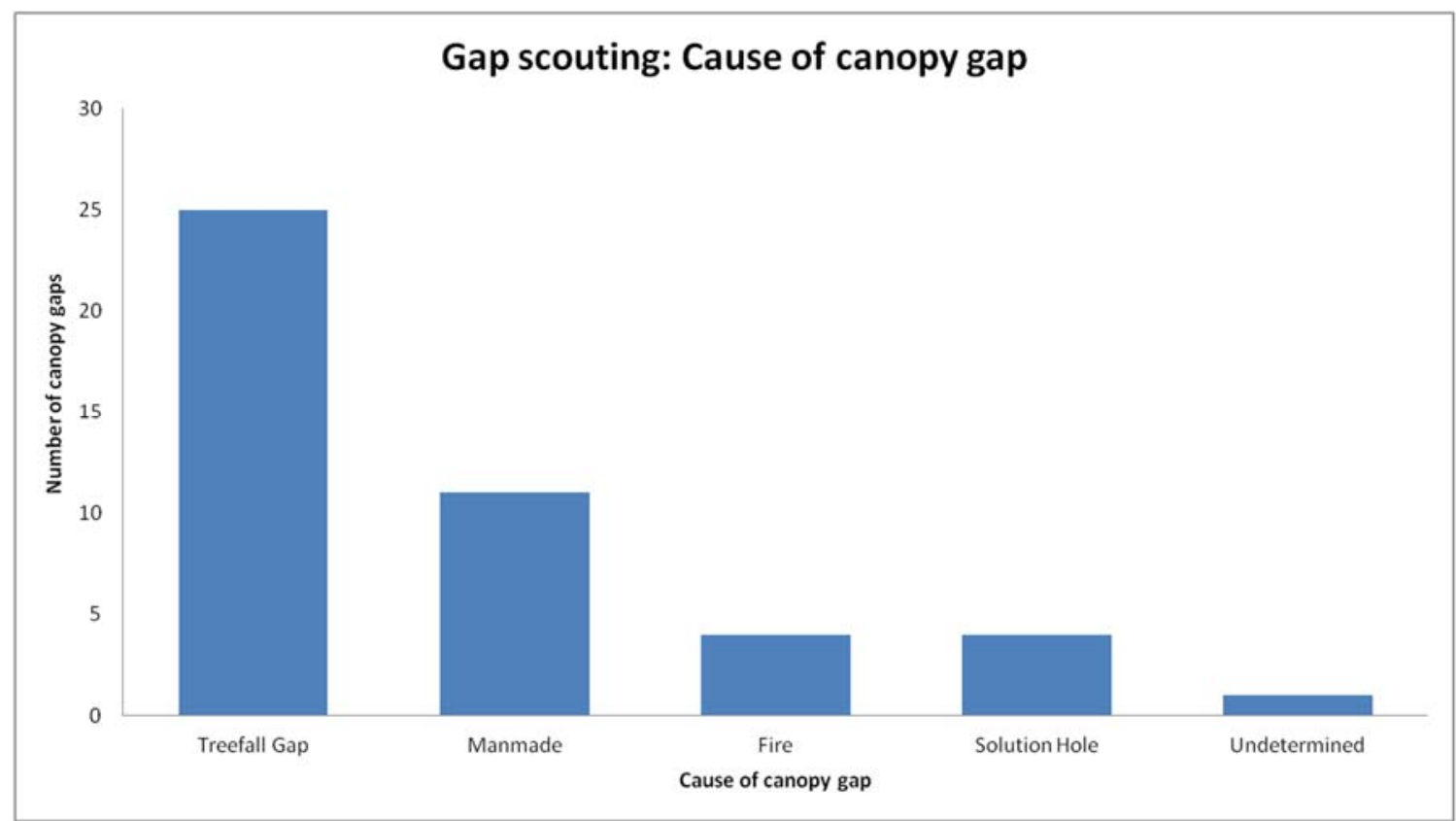

Figure 13: Gap scouting - cause of canopy gaps

Results from the initial scouting of canopy gaps. Over half of canopy gaps were natural treefall gaps. Anthropogenic gaps accounted for 11 canopy gaps. Fires and solution holes each accounted for four canopy gaps. One canopy gap was of indeterminate origin. 


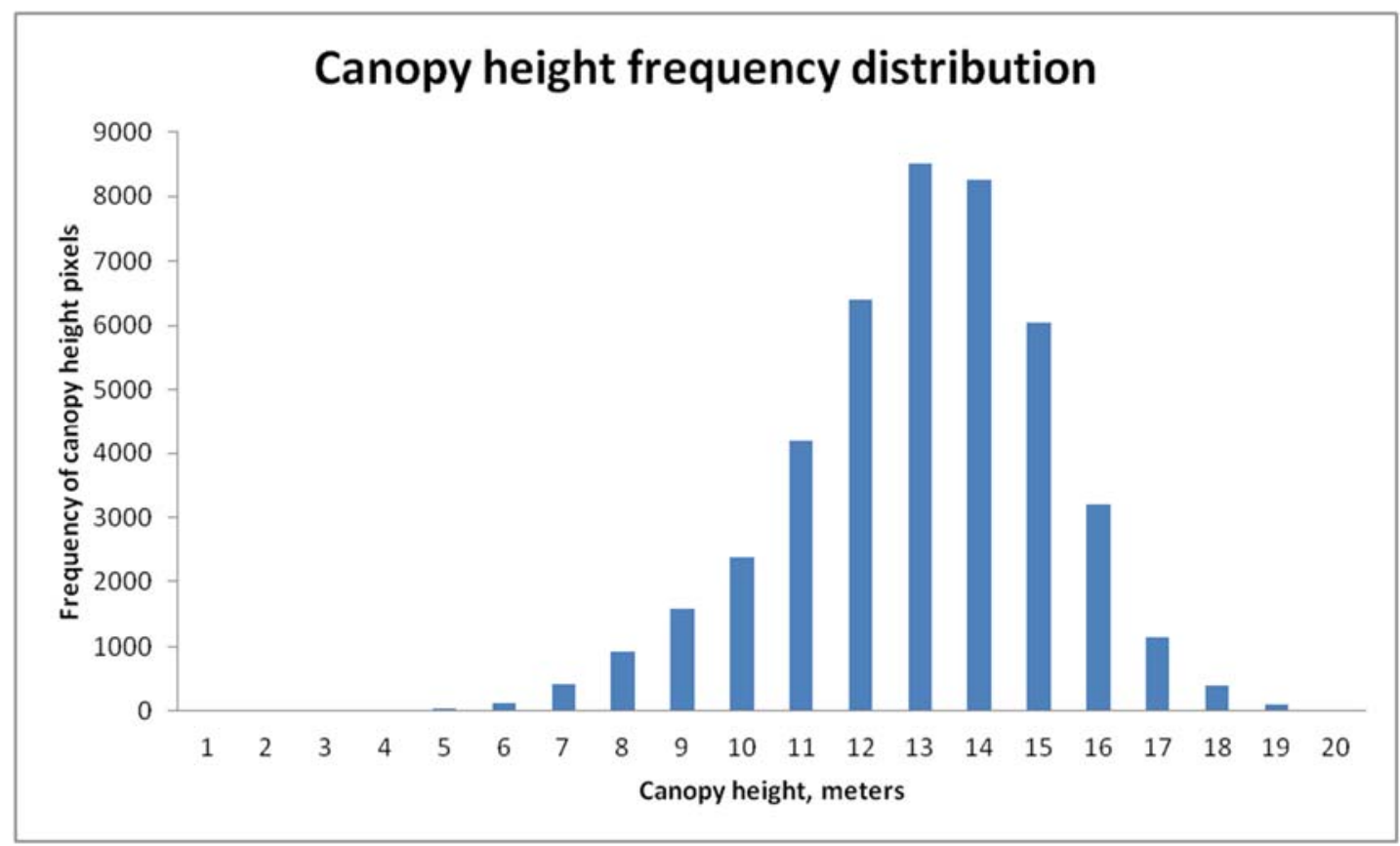

Figure 14: Canopy height histogram

Histogram of canopy height pixels in the study area, in meters. Canopy height values were detected with a coarser scale DCM than was used for identification of canopy gaps. The mean and median canopy heights were 11.71 and 12.70 meters. Pixels were ordered by value, and alternate pixels were selected, producing a dataset of 43,757 pixels. 


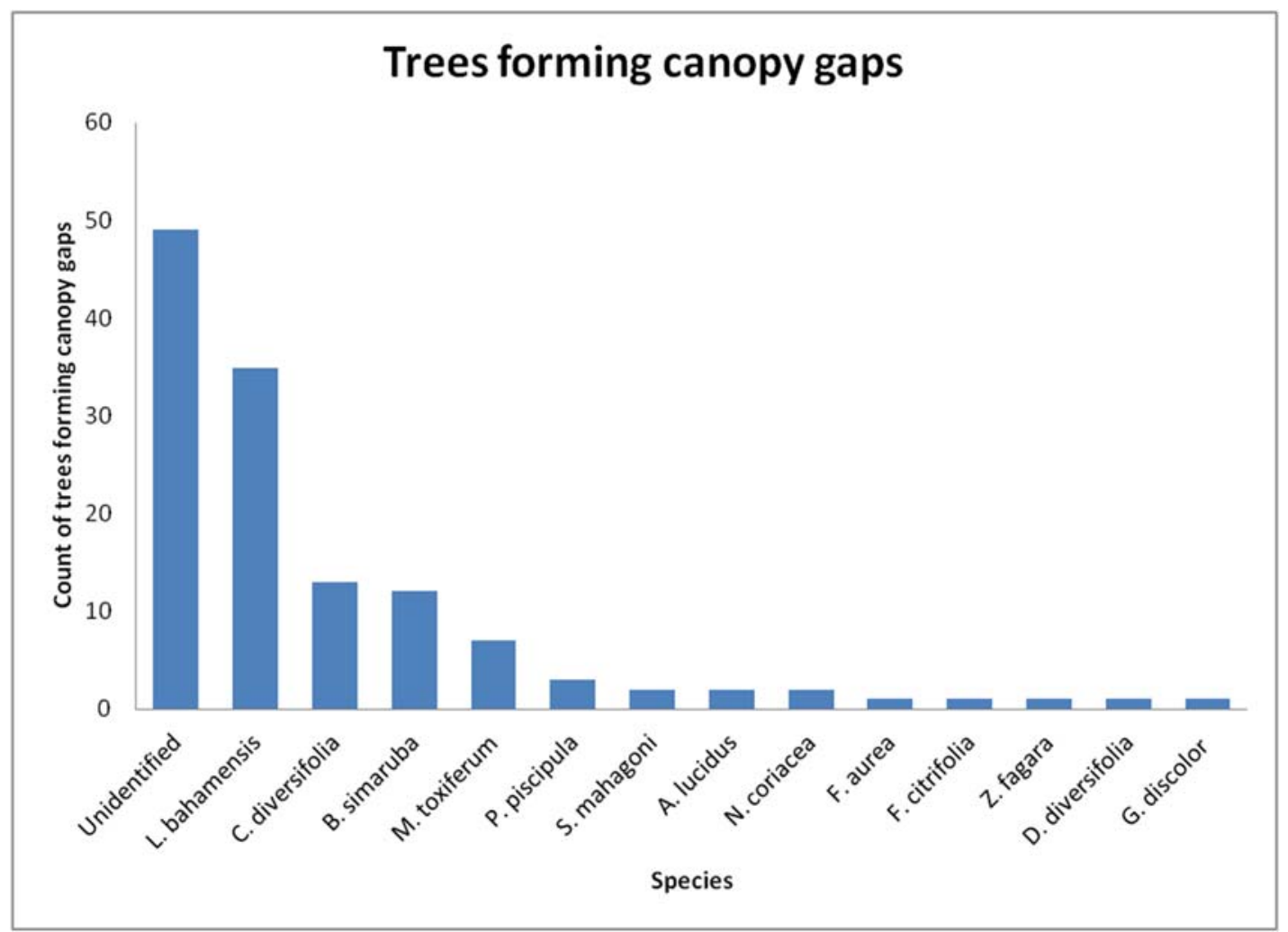

Figure 15: Trees forming canopy gaps

Tree species indentified as part of the formation of a treefall canopy gap. 49 trees were not identifiable to species, due to their state of decomposition. Some tree species in the hardwood hammock, especially some of the most common species found as gap formers, are able to survive uprooted for years, growing new stems from fallen trunks. 


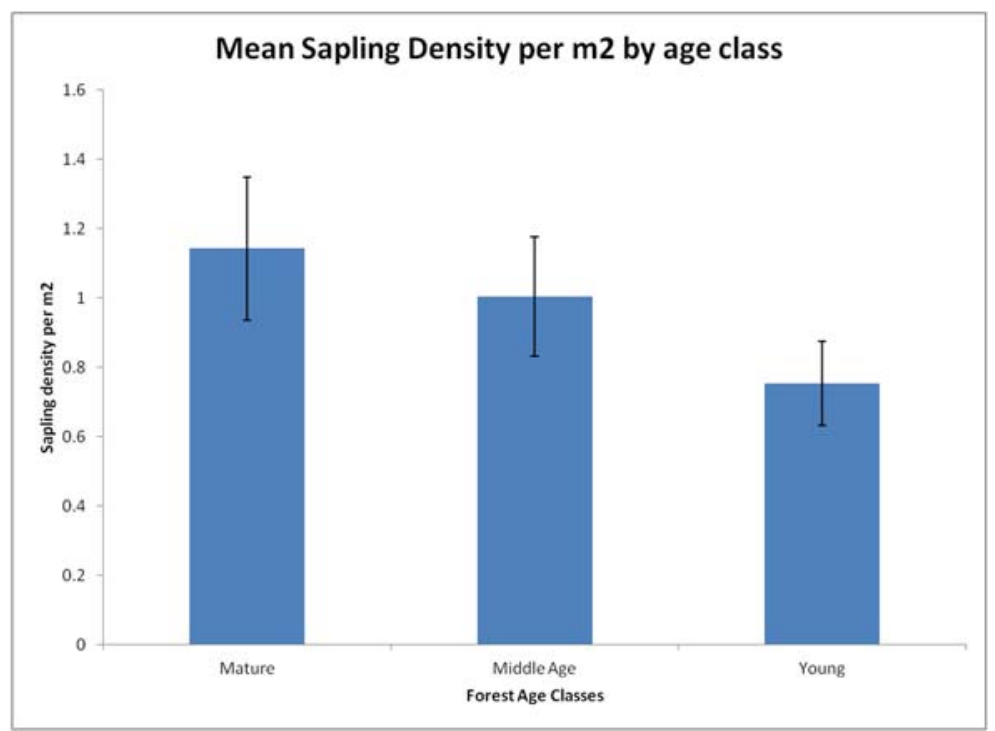

Figure 16: Mean sapling density by age class

Comparisons of mean canopy gap sapling density across forest ages. ANOVA indicates that the sapling density varied significantly across forest ages $(\mathrm{P}<0.005)$.

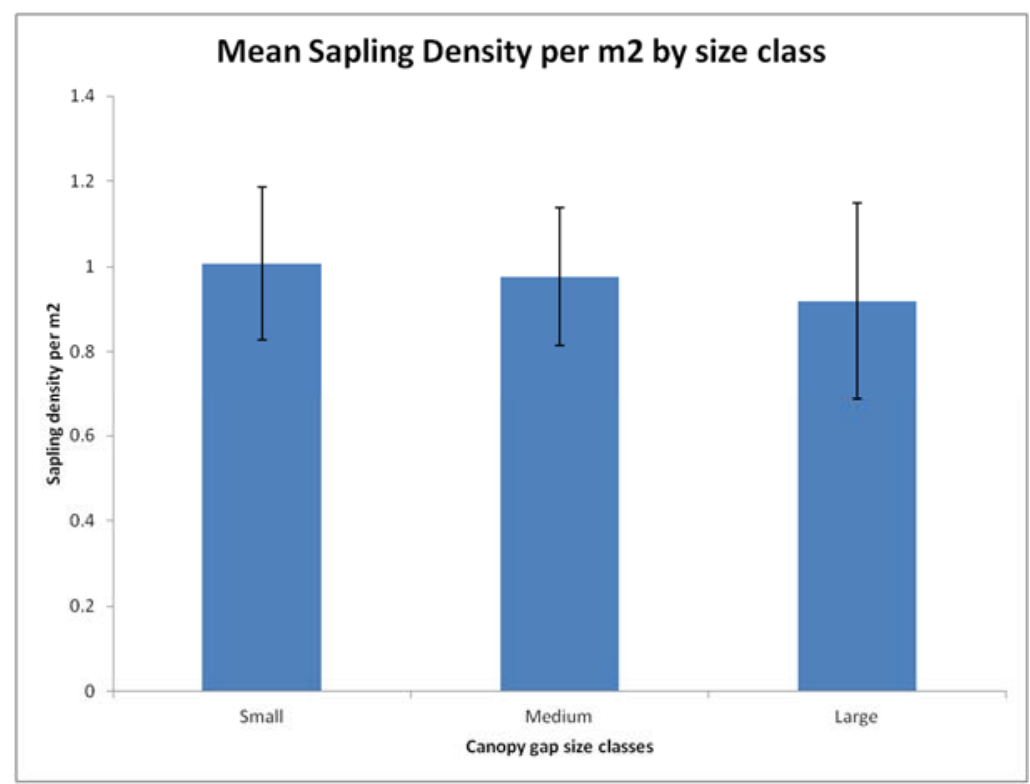

Figure 17: Mean sapling density by size class

Comparisons of mean canopy gap sapling density across canopy gap sizes. ANOVA indicates that the sapling density did not vary significantly $(\mathrm{P}=0.7794)$. 


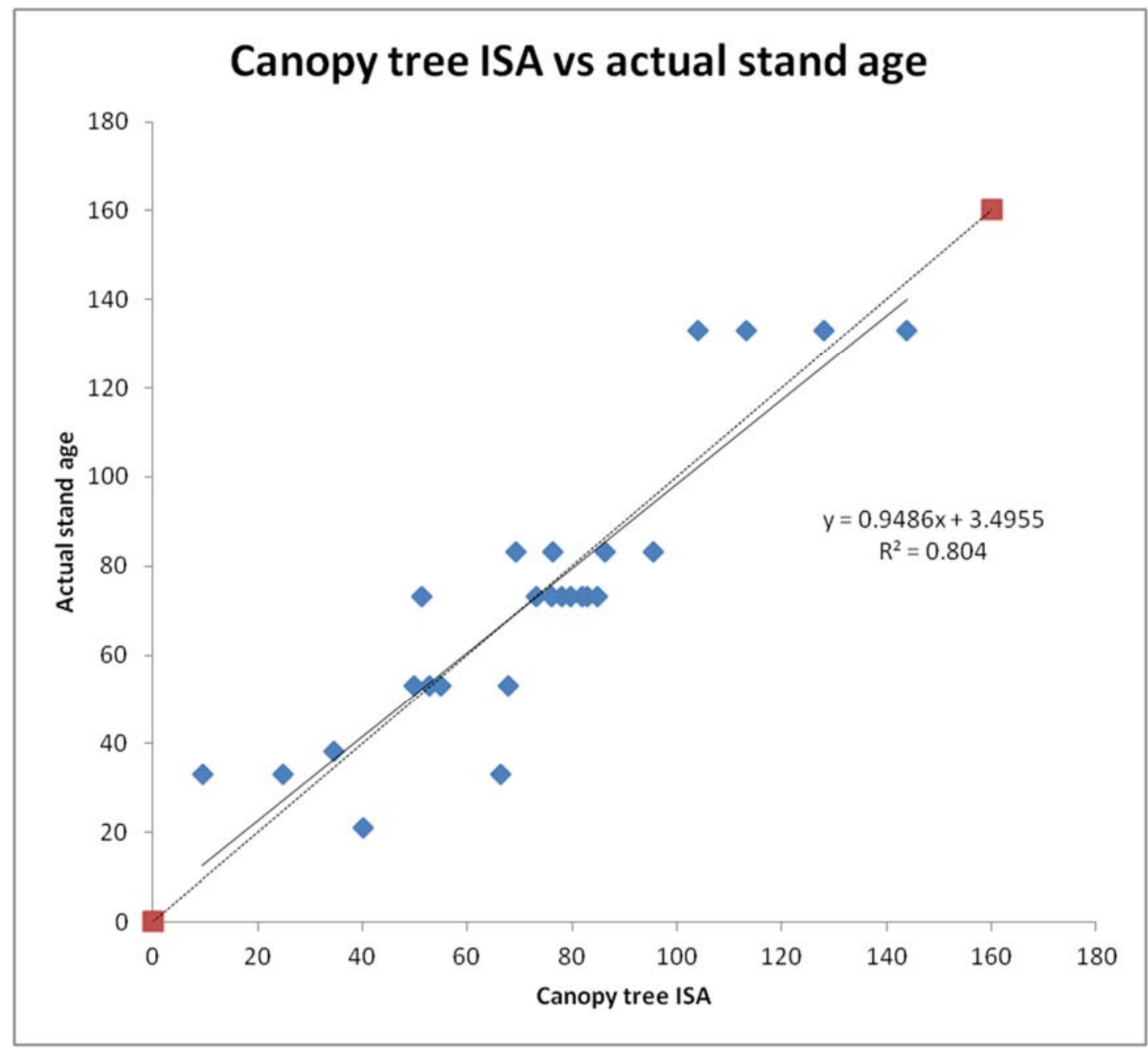

Figure 18: Transect canopy ISA vs actual age

ISA calculated from forest transect canopy trees against the actual stand age of the forest. The dashed line represents equal ISAs for small saplings and canopy trees; the solid line is the trend line calculated from the data, $\mathrm{R}^{2}=0.804$. 
Gap sapling vs canopy ISAs

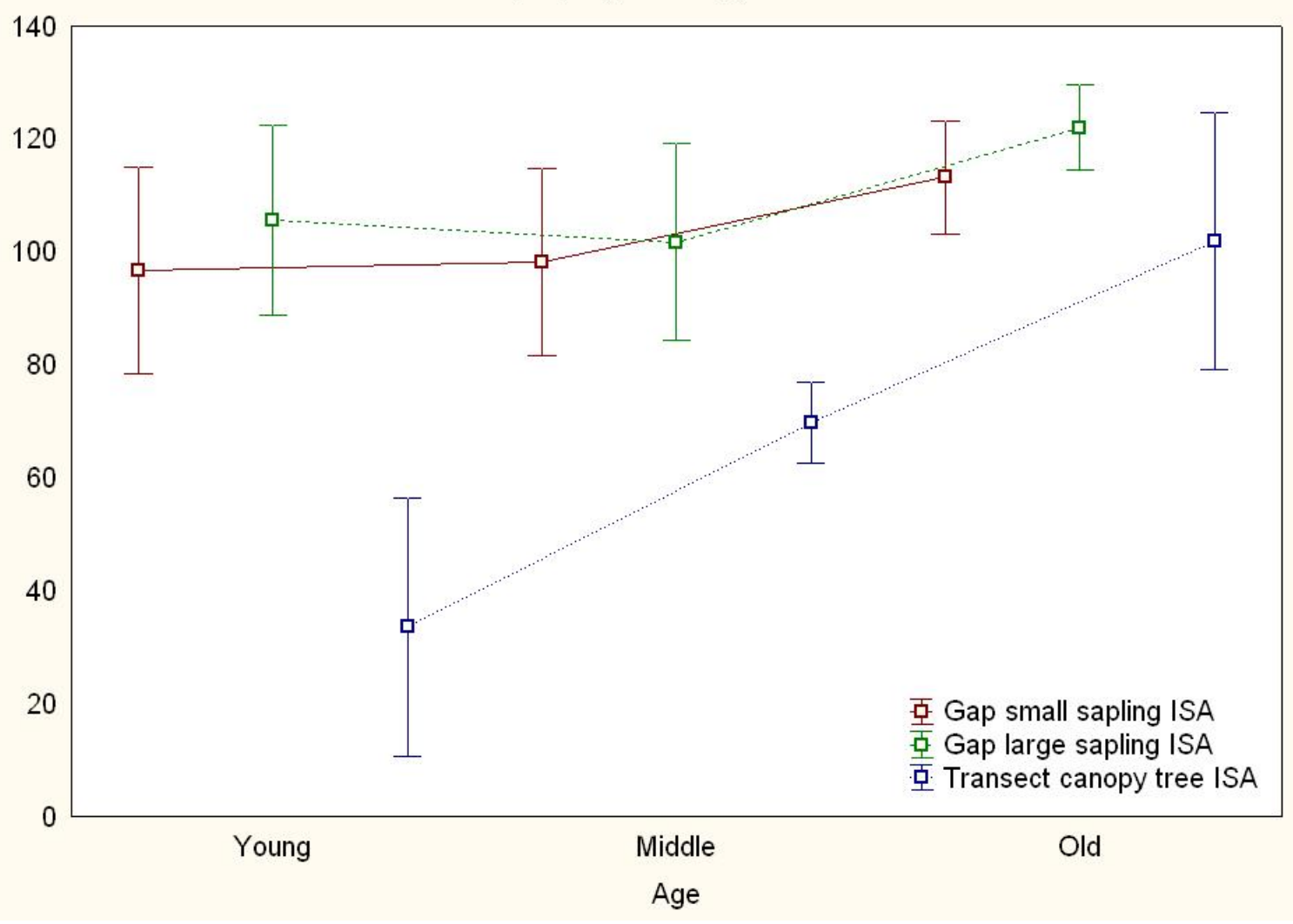

Figure 19: Gap saplings vs canopy ISAs

Small and large canopy gap sapling ISAs were compared to the ISAs of the canopy. Gap sapling ISAs were consistently higher than the canopy, with the largest difference in the young age class. 


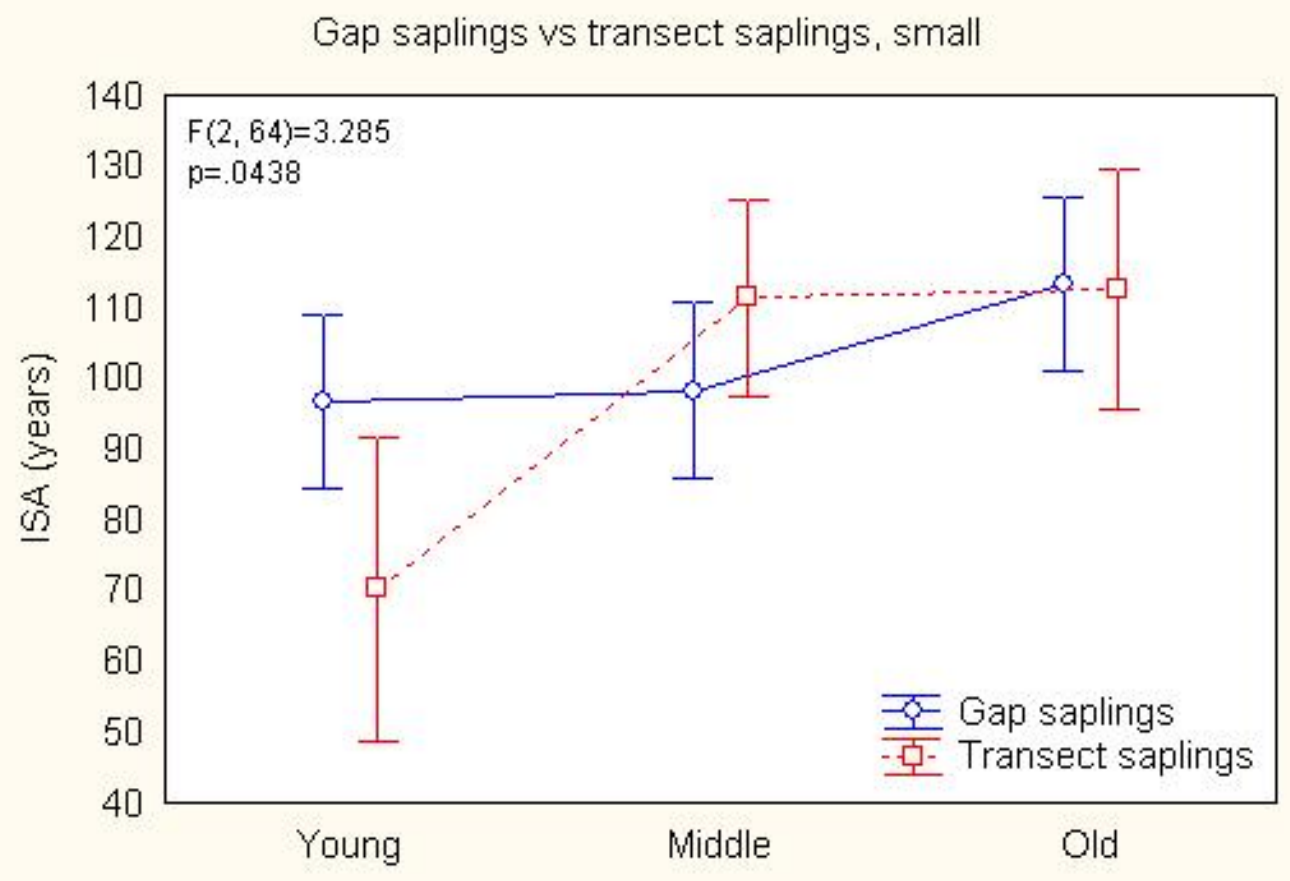

Gap saplings vs transect saplings, large

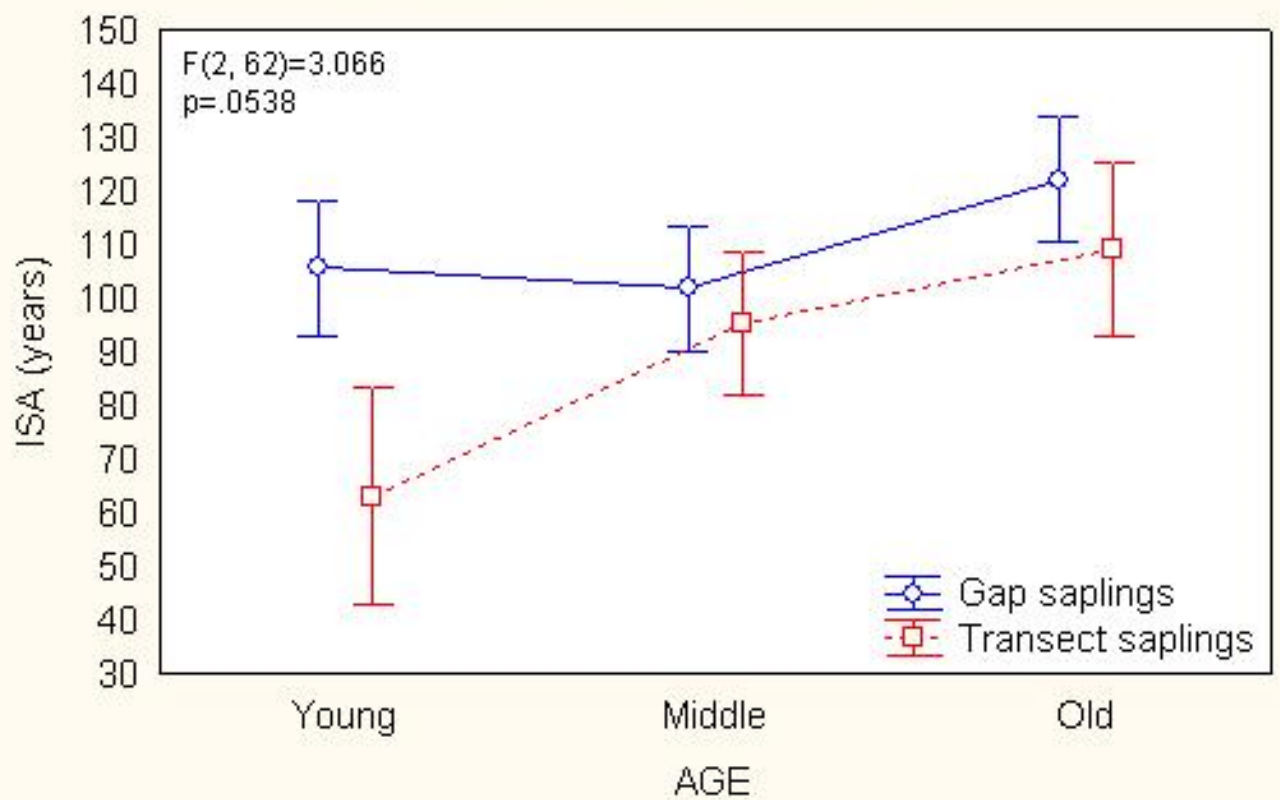

Figure 20: Gap saplings vs transect saplings

Two-way ANOVA indicated a significant difference in the interaction of age and gap/transect status of small saplings $(\mathrm{P}<0.05)$. Analysis of this interaction in large saplings was nearly significant $(\mathrm{P}=0.0538)$. In both cases, gap saplings in young forests had the greatest increase in ISAs compared to the forest transects. 


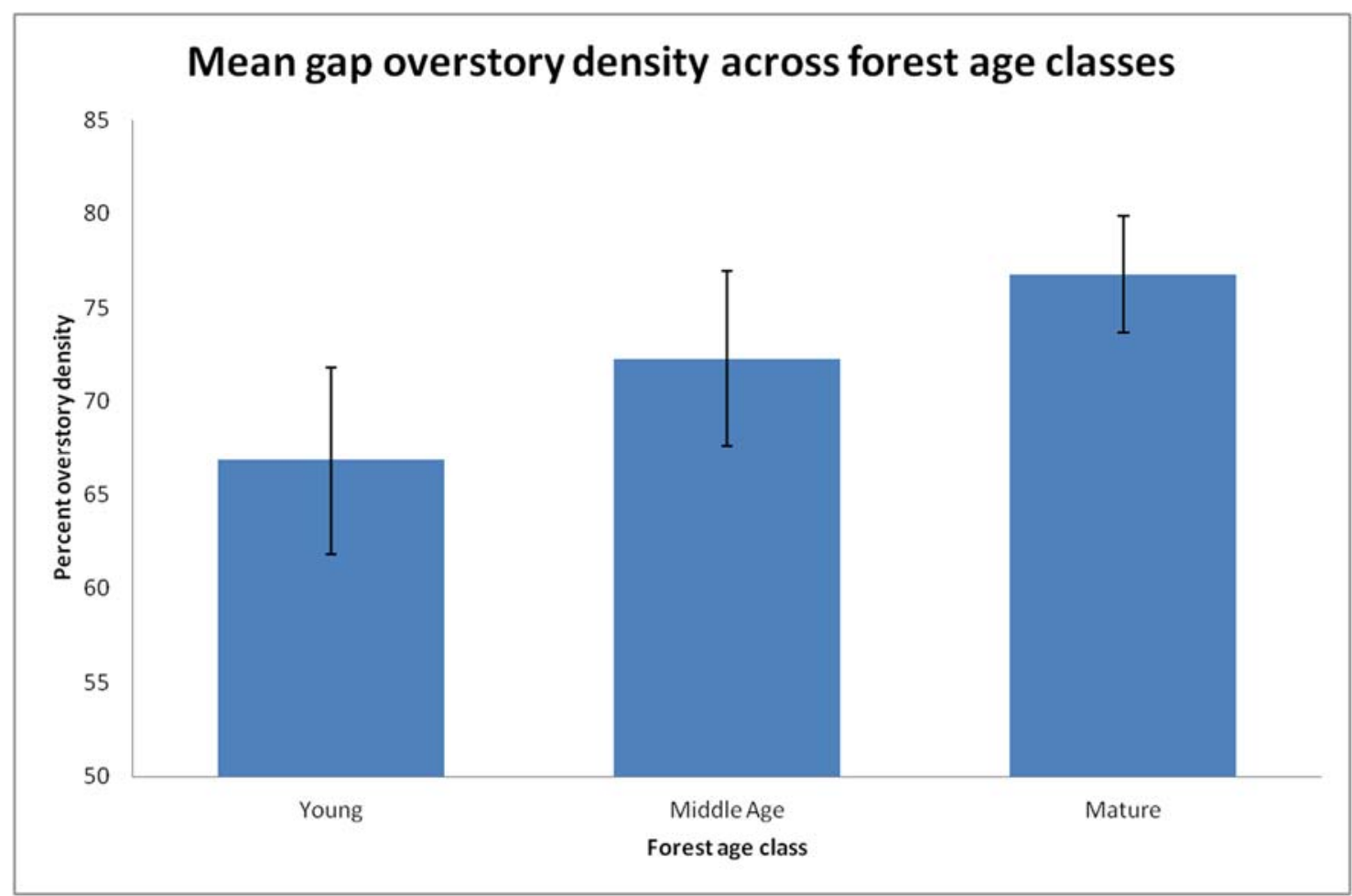

Figure 21: Gap overstory density by age class

Mean gap overstory density across forest age classes, with 95\% confidence interval shown. Mean gap overstory density increased with increasing age class. ANOVA two-factor with replication shows that overstory density varies significantly with age class $(\mathrm{P}<0.05)$. 


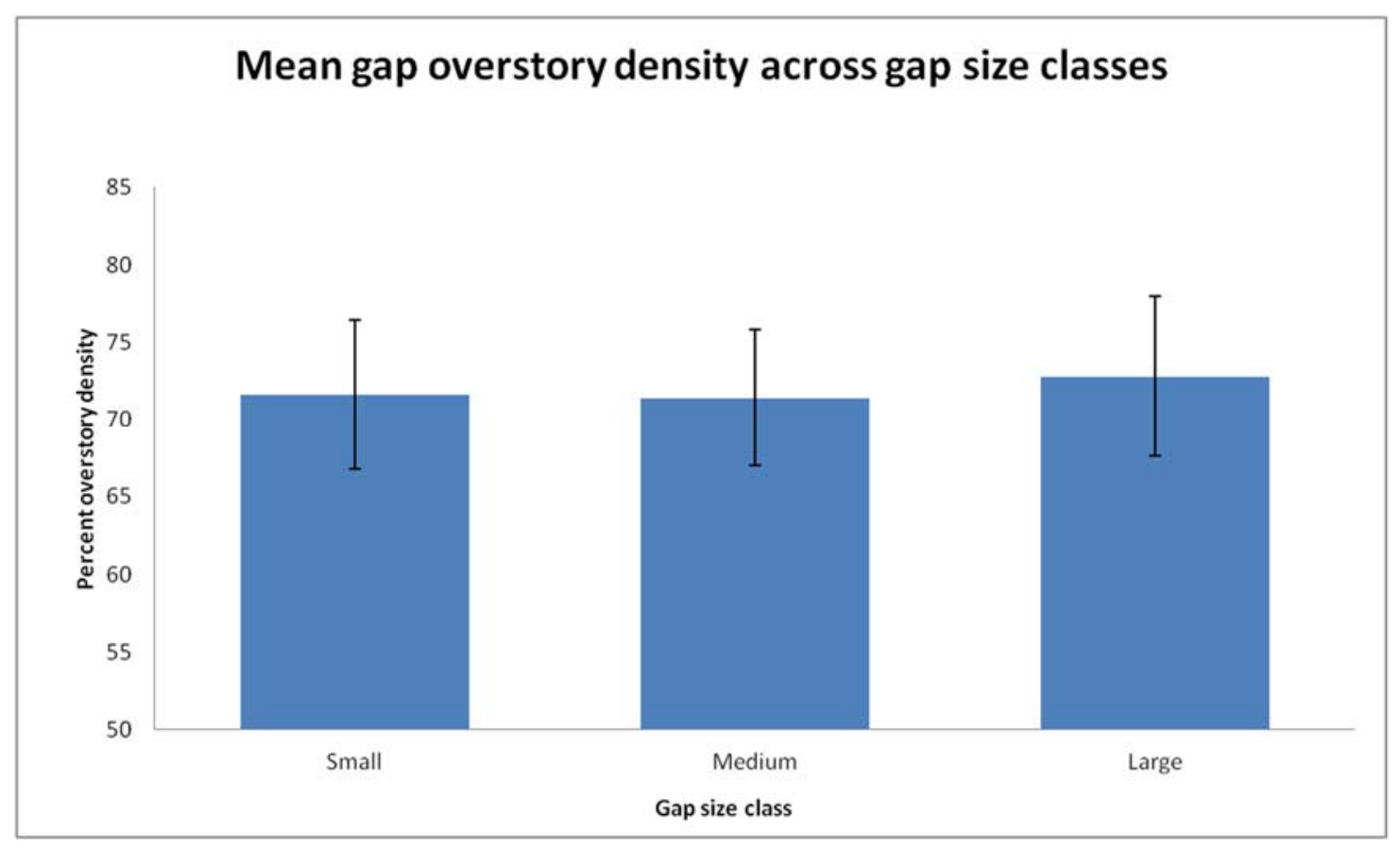

Figure 22: Gap overstory density by size class

Mean gap overstory density across forest age classes, with 95\% confidence interval shown. Mean gap overstory density showed no trend across canopy gap sizes. ANOVA two-factor with replication shows that overstory density did not vary significantly with age class $(\mathrm{P}=0.8941)$. 


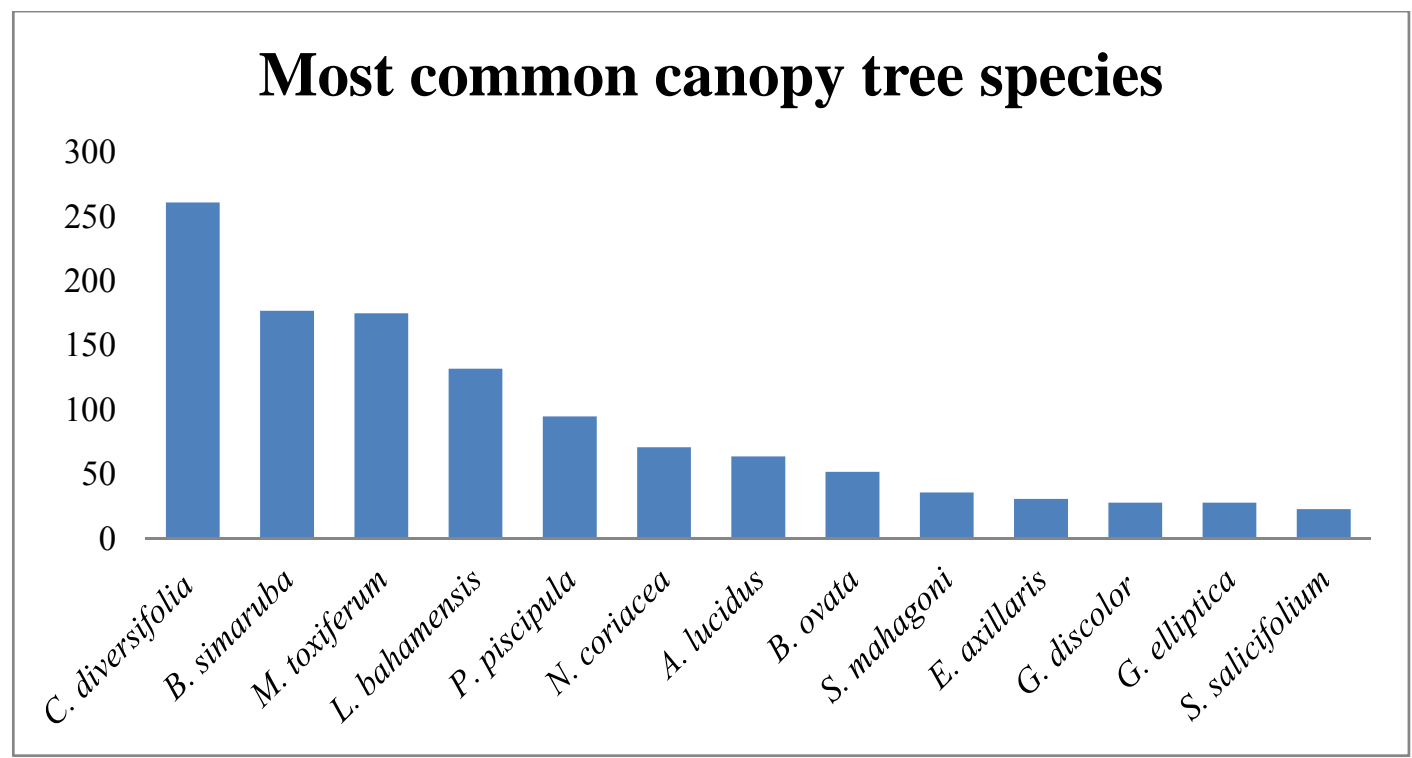

Figure 23: Most common canopy tree species, $\mathrm{n}>20$.

C. diversifolia was the most common tree surrounding the gaps, and appeared to be the most common species across the entire forest, present in all age classes. 


\section{WORKS CITED}

Alexander, T. R. (1974). Evidence of recent sea level rise derived from ecological studies on Key Largo, Florida. Environments of South Florida: present and past. Miami Geological Society, Coral Gables, Florida, 219-222.

Armentano, T. V., Jones, D. T., Ross, M. S., \& Gamble, B. W. (2002). Vegetation pattern and process in tree islands of the southern Everglades and adjacent areas. Tree islands of the Everglades, 225-282.

Asner, G. P., Kellner, J. R., Kennedy-Bowdoin, T, Knapp, D. E., Anderson, C, Martin, R. E. (2013) Forest Canopy Gap Distributions in the Southern Peruvian Amazon. PLoS ONE 8(4): e60875.

Barreda-Bautista, B., López-Caloca, A. A., Couturier, S., \& Silván-Cárdenas, J. L. (2011). Tropical Dry Forests in the Global Picture: The Challenge of Remote SensingBased Change Detection in Tropical Dry Environments, Instituto de Geografía Mexico.

Bazzaz, F. A. (1975). Plant species diversity in old-field successional ecosystems in southern Illinois. Ecology, 56(2), 485-488.

Brokaw, N. V. (1982). The definition of treefall gap and its effect on measures of forest dynamics. Biotropica, 158-160.

Brokaw, N. V. (1985). Treefalls, regrowth, and community structure in tropical forests. The Ecology of Natural Disturbance and Patch Dynamics. Academic Press, Inc.

Orlando.

Brokaw, N. V., \& Grear, J. S. (1991). Forest structure before and after Hurricane Hugo at three elevations in the Luquillo Mountains, Puerto Rico. Biotropica, 386-392.

Canham, C. D., Denslow, J. S., Platt, W. J., Runkle, J. R., Spies, T. A., \& White, P. S. (1990). Light regimes beneath closed canopies and tree-fall gaps in temperate and tropical forests. Canadian Journal of Forest Research, 20(5), 620-631.

Carrington, M.E., Ross, M.S., and Basit, A.F. Forest succession in tropical hardwood hammocks of the Florida Keys: Post-hurricane seedlings. Manuscript in preparation.

Childs, Colin. "Interpolating surfaces in ArcGIS spatial analyst." ArcUser, JulySeptember (2004): 32-35.

Denslow, J. S. (1980a). Gap partitioning among tropical rainforest trees. Biotropica, 4755.

Denslow, J. S. (1980b). Patterns of plant species diversity during succession under different disturbance regimes. Oecologia, 46(1), 18-21. 
Denslow, J. S. (1987). Tropical rainforest gaps and tree species diversity. Annual Review of Ecology and Systematics, 431-451.

Denslow, J. S. (1995). Disturbance and diversity in tropical rain forests: the density effect. Ecological applications, 5(4), 962-968.

Denslow, J. S., Ellison, A. M., \& Sanford, R. E. (1998). Treefall gap size effects on above-and below-ground processes in a tropical wet forest. Journal of Ecology, 86(4), 597-609.

Denslow, J. S., Schultz, J. C., Vitousek, P. M., \& Strain, B. R. (1990). Growth responses of tropical shrubs to treefall gap environments. Ecology, 165-179.

Dickinson, M. B., Hermann, S. M., \& Whigham, D. F. (2001). Low rates of background canopy-gap disturbance in a seasonally dry forest in the Yucatan Peninsula with a history of fires and hurricanes. Journal of tropical ecology,17(06), 895-902.

Duryea, M. L., Blakeslee, G. M., Hubbard, W. G., \& Vasquez, R. A. (1996). Wind and trees: A survey of homeowners after Hurricane Andrew. Journal of Arboriculture, 22, 44-50.

Elseroad, A. C., Fulé, P. Z., \& Covington, W. W. (2003). Forest road revegetation: effects of seeding and soil amendments. Ecological Restoration, 21(3), 180-185.

Engelbrecht, B. M., Comita, L. S., Condit, R., Kursar, T. A., Tyree, M. T., Turner, B. L., $\&$ Hubbell, S. P. (2007). Drought sensitivity shapes species distribution patterns in tropical forests. Nature, 447(7140), 80-82.

Franklin, J. F., Shugart, H. H., \& Harmon, M. E. (1987). Tree death as an ecological process. BioScience, 37(8), 550-556.

Gillespie, T. W. (2005). Predicting woody-plant species richness in tropical dry forests: a case study from South Florida, USA. Ecological Applications, 15(1), 27-37

Ghazoul, J. (2012). Book review: Tackling thorny issues in seasonally dry tropical forests. Frontiers of Biogeography, 3(4).

Grime, J. P. (1977). Evidence for the existence of three primary strategies in plants and its relevance to ecological and evolutionary theory. American Naturalist, 1169-1194.

Karim, A., \& Main, M. B. (2009). Habitat fragmentation and conservation strategies for a rare forest habitat in the Florida Keys archipelago. Urban Ecosystems, 12(3), 359-370.

Kern, C. C., Montgomery, R. A., Reich, P. B., \& Strong, T. F. (2013). Canopy gap size influences niche partitioning of the ground-layer plant community in a northern temperate forest. Journal of Plant Ecology, 6(1), 101-112.

Lemmon, P. E. (1956). A spherical densiometer for estimating forest overstory density. Forest Science, 2(4), 314-320. 
Lugo, A. E., Medina, E., Trejo-Torres, J. C., \& Helmer, E. (2010). Botanical and Ecological Basis for the Resilience of Antillean Dry Forests. Neotropical Savannas and Seasonally Dry Forests: Plant Diversity, Biogeography, and Conservation, 359.

Maass, J. M. (1995). Conversion of tropical dry forest to pasture and agriculture. In Bullock, S. H., Mooney, H. A., Medina, A. (Editors), Seasonally Dry Tropical Forests. Cambridge: Cambridge University Press.

McInerney, D. O., Suarez-Minguez, J., Valbuena, R., \& Nieuwenhuis, M. (2010). Forest canopy height retrieval using LiDAR data, medium-resolution satellite imagery and $\mathrm{kNN}$ estimation in Aberfoyle, Scotland. Forestry, 83(2), 195-206.

Mueller-Dombois, D. (1983). Canopy dieback and successional processes in Pacific forests. Pacific Science, 37(4), 317-325.

Murphy, P. G., \& Lugo, A. E. (1986). Ecology of tropical dry forest. Annual review of ecology and systematics, 67-88.

Odum, E. P. (1969). The strategy of ecosystem development. Sustainability, 164, 58.

Pickett, S. T. A. (1976). Succession: an evolutionary interpretation. American Naturalist, 107-119.

Kern, C. C., Montgomery, R. A., Reich, P. B., \& Strong, T. F. (2013). Canopy gap size influences niche partitioning of the ground-layer plant community in a northern temperate forest. Journal of Plant Ecology, 6(1), 101-112.

Ricklefs, R. E. (1977). Environmental heterogeneity and plant species diversity: a hypothesis. American Naturalist, 376-381.

Rodríguez-Calcerrada, J., Pardos, J. A., Gil, L., \& Aranda, I. (2008). Ability to avoid water stress in seedlings of two oak species is lower in a dense forest understory than in a medium canopy gap. Forest ecology and management,255(3), 421-430.

Ross, M. S., Carrington, M., Flynn, L. J., \& Ruiz, P. L. (2001). Forest Succession in Tropical Hardwood Hammocks of the Florida Keys: Effects of Direct Mortality from Hurricane Andrew. Biotropica, 33(1), 23-33.

Ross, M. S., Coultas, C. L., \& Hsieh, Y. P. (2003). Soil-productivity relationships and organic matter turnover in dry tropical forests of the Florida Keys. Plant and Soil, 253(2), 479-492.

Ross, M. S., O'Brien, J. J., \& Flynn, L. J. (1992). Ecological site classification of Florida Keys terrestrial habitats. Biotropica, 488-502.

Ross, M. S., Ogurcak, D. E., Sah, J. P., \& Ruiz, P. L. (2010). Using Florida Keys reference sites as a standard for restoration of forest structure in Everglades tree islands. International Journal of Forestry Research, 2010. 
Schnitzer, S. A., Mascaro, J., \& Carson, W. P. (2008). Treefall gaps and the maintenance of plant species diversity in tropical forests. Tropical Forest Community Ecology, 196209.

Swaine, M. D., Lieberman, D., \& Hall, J. B. (1990). Structure and dynamics of a tropical dry forest in Ghana. Vegetatio, 88(1), 31-51.

Vandermeer, J., de la Cerda, I. G., Boucher, D., Perfecto, I., \& Ruiz, J. (2000). Hurricane disturbance and tropical tree species diversity. Science, 290(5492), 788-791.

Vitousek, P. M., \& Denslow, J. S. (1986). Nitrogen and phosphorus availability in treefall gaps of a lowland tropical rainforest. The Journal of Ecology, 1167-1178.

Welden, C. W., Hewett, S. W., Hubbell, S. P., \& Foster, R. B. (1991). Sapling survival, growth, and recruitment: relationship to canopy height in a neotropical forest. Ecology, 72(1), 35-50.

Whitmore, T. C. (1989). Canopy gaps and the two major groups of forest trees. Ecology, 70(3), 536-538.

Zhang, K. (2008). Identification of gaps in mangrove forests with airborne LIDAR. Remote Sensing of Environment, 112(5), 2309-2325.

Zhang, K., Simard, M., Ross, M., Rivera-Monroy, V. H., Houle, P., Ruiz, P., \& Whelan, K. (2008). Airborne laser scanning quantification of disturbances from hurricanes and lightning strikes to mangrove forests in Everglades National Park, USA. Sensors, 8(4), 2262-2292.

ESRI (2014). ArcGIS Desktop Help: Release 10.2. Redlands, CA: Environmental Systems Research Institute. 